\title{
The Impact of Flight Hardware Scavenging on Space Logistics
}

Richard C. Oeftering

Glenn Research Center, Cleveland, Ohio 


\section{NASA STI Program . . . in Profile}

Since its founding, NASA has been dedicated to the advancement of aeronautics and space science. The NASA Scientific and Technical Information (STI) program plays a key part in helping NASA maintain this important role.

The NASA STI Program operates under the auspices of the Agency Chief Information Officer. It collects, organizes, provides for archiving, and disseminates NASA's STI. The NASA STI program provides access to the NASA Aeronautics and Space Database and its public interface, the NASA Technical Reports Server, thus providing one of the largest collections of aeronautical and space science STI in the world. Results are published in both non-NASA channels and by NASA in the NASA STI Report Series, which includes the following report types:

- TECHNICAL PUBLICATION. Reports of completed research or a major significant phase of research that present the results of NASA programs and include extensive data or theoretical analysis. Includes compilations of significant scientific and technical data and information deemed to be of continuing reference value. NASA counterpart of peer-reviewed formal professional papers but has less stringent limitations on manuscript length and extent of graphic presentations.

- TECHNICAL MEMORANDUM. Scientific and technical findings that are preliminary or of specialized interest, e.g., quick release reports, working papers, and bibliographies that contain minimal annotation. Does not contain extensive analysis.

- CONTRACTOR REPORT. Scientific and technical findings by NASA-sponsored contractors and grantees.
- CONFERENCE PUBLICATION. Collected papers from scientific and technical conferences, symposia, seminars, or other meetings sponsored or cosponsored by NASA.

- SPECIAL PUBLICATION. Scientific, technical, or historical information from NASA programs, projects, and missions, often concerned with subjects having substantial public interest.

- TECHNICAL TRANSLATION. Englishlanguage translations of foreign scientific and technical material pertinent to NASA's mission.

Specialized services also include creating custom thesauri, building customized databases, organizing and publishing research results.

For more information about the NASA STI program, see the following:

- Access the NASA STI program home page at http://www.sti.nasa.gov

- E-mail your question via the Internet to help@ sti.nasa.gov

- Fax your question to the NASA STI Help Desk at 443-757-5803

- Telephone the NASA STI Help Desk at 443-757-5802

- Write to: NASA Center for AeroSpace Information (CASI) 7115 Standard Drive Hanover, MD 21076-1320 


\section{The Impact of Flight Hardware Scavenging on Space Logistics}

Richard C. Oeftering

Glenn Research Center, Cleveland, Ohio

Prepared for the

Space 2010 Conference and Exposition

sponsored by the American Institute of Aeronautics and Astronautics

Anaheim, California, August 30 to September 2, 2010

National Aeronautics and

Space Administration

Glenn Research Center

Cleveland, Ohio 44135 
This report contains preliminary findings, subject to revision as analysis proceeds.

Trade names and trademarks are used in this report for identification only. Their usage does not constitute an official endorsement, either expressed or implied, by the National Aeronautics and Space Administration.

Level of Review: This material has been technically reviewed by technical management.

Available from

NASA Center for Aerospace Information 7115 Standard Drive

Hanover, MD 21076-1320
National Technical Information Service 5301 Shawnee Road Alexandria, VA 22312

Available electronically at http://www.sti.nasa.gov 


\title{
The Impact on Flight Hardware Scavenging on Space Logistics
}

\author{
Richard C. Oeftering \\ National Aeronautics and Space Administration \\ Glenn Research Center \\ Cleveland, Ohio 44135
}

\begin{abstract}
For a given fixed launch vehicle capacity the logistics payload delivered to the moon may be only roughly $20 \%$ of the payload delivered to the International Space Station (ISS). This is compounded by the much lower flight frequency to the moon and thus low availability of spares for maintenance. This implies that lunar hardware is much more scarce and more costly per kilogram than ISS and thus there is much more incentive to preserve hardware. The Constellation Lunar Surface System (LSS) program is considering ways of utilizing hardware scavenged from vehicles including the Altair lunar lander. In general, the hardware will have only had a matter of hours of operation yet there may be years of operational life remaining. By scavenging this hardware the program, in effect, is treating vehicle hardware as part of the payload. Flight hardware may provide logistics spares for system maintenance and reduce the overall logistics footprint. This hardware has a wide array of potential applications including expanding the power infrastructure, and exploiting in-situ resources. Scavenging can also be seen as a way of recovering the value of, literally, billions of dollars worth of hardware that would normally be discarded. Scavenging flight hardware adds operational complexity and steps must be taken to augment the crew's capability with robotics, capabilities embedded in flight hardware itself, and external processes. New embedded technologies are needed to make hardware more serviceable and scavengable. Process technologies are needed to extract hardware, evaluate hardware, reconfigure or repair hardware, and reintegrate it into new applications. This paper also illustrates how scavenging can be used to drive down the cost of the overall program by exploiting the intrinsic value of otherwise discarded flight hardware.
\end{abstract}

\section{Introduction}

The operational support costs of existing space capabilities is often a barrier to establishing new capabilities under limited budgets. The Constellation Program, for example called for retiring the Space Shuttle after 2010 and International Space Station (ISS) after 2015. To prevent a lunar outpost from becoming too expensive to operate, supportability must be addressed in the architecture development phase and infused throughout the architecture.

Lunar Surface Systems (LSS) will be difficult and costly to support by conventional logistics. The existing International Space Station (ISS) relies on robust logistics infrastructure provided by the Space Shuttle and Russian Progress and Soyuz vehicles. In comparison, the payload capacity for any given launch vehicle to the moon is around $1 / 5$ th that of ISS in low earth orbit (LEO). This implies that space transportation costs amortized on the final landed vehicle mass makes the hardware 5 times more valuable per kilogram. Given that transporting a payload to LEO is assumed to be $\$ 20,000$ per kilogram the additional transportation to the lunar surface is about $\$ 100,000$ per kilogram.

Lunar Surface System support cost is further exacerbated by the fact that logistics is one way. For ISS, Space Shuttle logistics allows any faulty hardware to be replaced and sent to Earth for repair and eventually returned to the ISS. This closed loop maintenance preserves valuable hardware. Unlike ISS, however, lunar systems will have no option to return hardware for servicing. The costly unit must be discarded and a replacement must be delivered from Earth. An alternative is to perform an in-situ repair process to restore it. Many of the replacement components may be found in the lunar lander flight hardware.

At a much larger scale, each crewed lunar mission results in the abandonment of the Altair lunar lander Decent Module and the total destruction of the Ascent Module. Further, the Orion Service Module is discarded and only a portion of the Orion's Crew Module is reusable at the end of each mission. To minimize cost NASA must develop methods of recovering high value flight hardware. If entire vehicles cannot be reused, then next best option is to scavenge (or salvage) system hardware. 


\section{The Case for Scavenging Lunar Assets}

\section{A. The Cost of Space Flight Assets}

The value of scavenging can be illustrated by comparing the Altair lander in a Crewed Mission with that of the robotic Cargo Missions. As noted earlier, each crewed lunar mission results in the abandonment of the Altair lunar lander Decent Module (DM), destruction of the Ascent Module and the Orion Service Module. Using a conservative mass fraction calculation for a vehicle traveling from Low Earth Orbit (LLO) the estimate space transportation cost per kilogram is:

- $\$ 60,000 / \mathrm{kg}$ for Orion to Low Lunar Orbit

- $\$ 100,000 / \mathrm{kg}$ for Altair to the Lunar Surface

Delivered Mass:

- Orion to Lunar Orbit Mass $=20,200 \mathrm{~kg}$

- Altair Landed Mass $=20,100 \mathrm{~kg}$

- Cargo Landed Mass $=26,100 \mathrm{~kg}$

\section{Crewed Mission Flight Assets:}

- Orion $=(20,200 \mathrm{~kg} \mathrm{x} 60,000 \$ / \mathrm{kg})=\$ 1.21$ Billion

- Altair $=(21,000 \mathrm{~kg} \times 100,000 \$ / \mathrm{kg})=\$ 2.01$ Billion

- Payload Only $=(1500 \mathrm{~kg} \times 100,000 \$ / \mathrm{kg})=\$ 0.150$ Billion

- Altair Descent Module $=(12,900 \times 100,000 \$ / \mathrm{kg})=\$ 1.29$ Billion

Cargo Lander Transportation Cost and Post Flight Assets:

- Cargo Lander + Payload Mass $=(26,100 \mathrm{~kg} \times 100,000 \$ / \mathrm{kg})=\$ 2.61$ Billion

- Payload Only $=(14,500 \mathrm{~kg} \times 100,000 \$ / \mathrm{kg})=\$ 1.45$ Billion

Note that the Cargo Lander payload capacity is higher since the Altair Cargo Lander does not carry the Orion vehicle through propulsive braking required to enter lunar orbit.

Table 1: Comparison of Crewed Missions versus Cargo Missions

\begin{tabular}{|c|c|c|c|}
\hline \multicolumn{2}{|c|}{ Crewed Mission } & \multicolumn{2}{c|}{ Cargo Mission } \\
\hline Elements & Transport Cost & Elements & Transport Cost \\
\hline Altair + Orion & $\$ 3.22 \mathrm{~B}$ & Altair Cargo Lander & $\$ 2.6 \mathrm{~B}$ \\
\hline Payload Value & $\$ 0.15 \mathrm{~B}(5 \%)$ & Payload Value & $\$ 1.45 \mathrm{~B}(56 \%)$ \\
\hline Payload + DM Reuse Value & $\$ 1.44 \mathrm{~B}(45 \%)$ & Payload +CL Reuse Value & $\$ 2.6 \mathrm{~B}(100 \%)$ \\
\hline
\end{tabular}

After the crew departs and no effort is made to reuse the DM mass then only $1500 \mathrm{~kg}$ of payload remains or $5 \%$. If the DM mass was fully utilized the program recovers as much as $45 \%$ of the $\$ 3.22 \mathrm{~B}$ mission value. For the Cargo mission $100 \%$ of the systems remain intact for lunar surface application. If only the cargo is utilized then only $56 \%$ of the transportation cost is utilized. If the complete cargo lander is fully reused then the recovered value approaches $100 \%$ of the $\$ 2.6$ Billion.

This illustration provides a powerful argument in favor of preserving and scavenging valuable flight hardware and using it to build a space infrastructure. The payoff per mission can be over a billion dollars and indicates the value of the technology investment. 


\section{B. What is Hardware Scavenging?}

The term scavenging originally arose in the context of recovering or scavenging residual propellants and fluids after the Altair landed for use as consumables for lunar surface systems. The term was extended to cover anything including electrical, mechanical and structural hardware. The scavenging is motivated by the desire to recover valuable hardware from the lander and preserve the value for lunar applications. This hardware is expected to be in very good condition. Even though a lander Descent Module is spent and served its original role, it has only accumulated a matter of hours or in some cases minutes of operation. Some hardware, like avionics and structures, may have decades of remaining life. The Altair vehicle can be scavenged for residual propellant, propulsion and structures hardware, avionics and electrical systems.

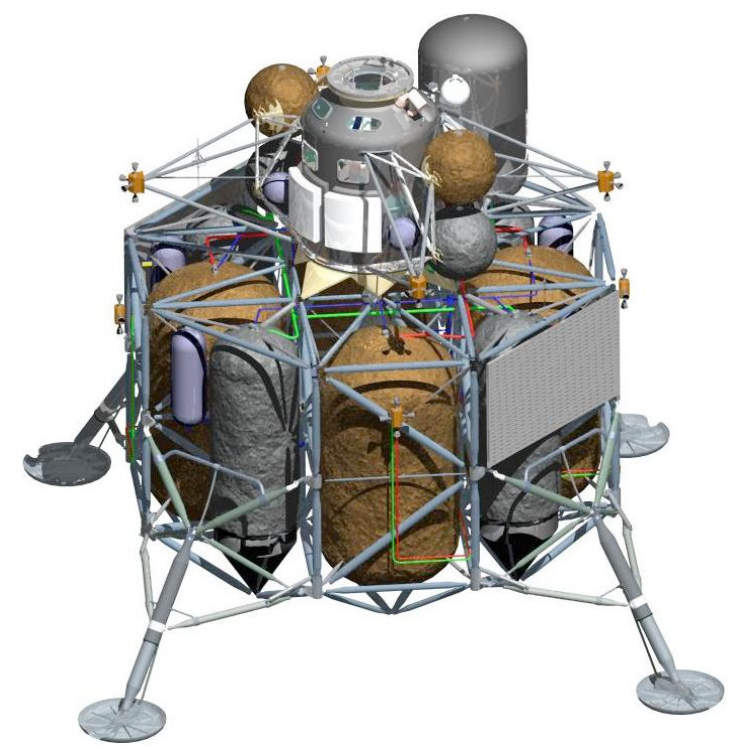

Figure 1: Altair Lander has tons of reusable hardware. Note that the image shows the sortie version of the Altair with the airlock module that is not used on outpost missions. (Credit: NASA Constellation Program)

\section{What Can Scavenging Provide?}

Scavenged hardware can be used in multiple applications. The primary initial application is to provide spares for either lunar surface systems or later Altair landers. Once the primary need for spares is satisfied the secondary application is to provide hardware for building infrastructure. Avionics and electrical are particularly suited to be adapted to new lunar applications. Mechanisms and structures are more tailored for a specific role and less easily reconfigured. In many cases, structures and mechanisms may be scavenged and reused at the component level. In some cases the material may be scavenged and reused in in-situ repair and fabrication. Scavenging is most fruitful if performed across the full range of integration levels from system level down to component and materials.

\section{Scavenging as Part of Supportability Strategy}

There have been earlier studies that investigated how the lunar lander can be reused. However the studies tend to focus on a specific reuse application. For example, a recent study focused on a concept to redesign propellant tanks so they could be reused as habitat and storage. ${ }^{1}$ After multiple missions, however, the result is a surplus of habitats and a vehicle that may be less than optimized for flight. In this paper, the focus is on how scavenging and reuse supports a broad array of applications under an overall supportability strategy.

It is important to establish a design philosophy to assure that supportability has visibility in the development of the system architecture. The features and technology that make a system supportable and affordable must be woven into the design much like reliability and safety. As system designers struggle to develop a viable design the issue of supportability tends to be relegated to the backburner and eventually becomes a burden for flight operations. ${ }^{2}$ 
The ISS was the first permanent flight facility where maintenance operations influenced the hardware design. Flight operations involves a crew workload centric view and need to minimize crew time and training for maintenance tasks. For ISS the result was to create the modular system designed around the concept of "Easy to Replace" modular Orbital Replacement Units (ORU). The ORU approach succeeds in minimizing crew time but at the expense of logistics mass. A component failure of a few grams requires the replacement of an entire ORU weighing many kilograms. Without an in-situ means of repairing the ORU, it must be returned to Earth for repairs. This is acceptable if logistics is supported by round trip Space Shuttle flights. Such an infrastructure is not practical for lunar operations. With the end of the Space Shuttle program ISS will no longer have such an infrastructure and will also need to deal with greater in-situ maintenance.

Lunar Surface Systems have a much harsher operating environment than ISS and thus demand more in-situ maintenance. Unlike the Space Shuttle supported ISS, lunar operations can be characterized by logistics scarcity. A new supportability strategy is needed to satisfy maintenance needs and the logistics and operational constraints. The strategy will incorporate new embedded technologies that make maintenance more supportable and new process technologies that will minimize logistics and crew time. Scavenging of flight hardware is part of an overall strategy to reduce and where possible eliminate dependency on Earth based logistics.

Scavenging is a part of Lunar Surface Systems (LSS) Supportability Plan and is described in a recent technology roadmap. ${ }^{3}$ Beyond maintenance and repair, scavenged hardware can be used to build infrastructure such as power, communications and even in-situ resource systems and other elements that make lunar operations more effective.

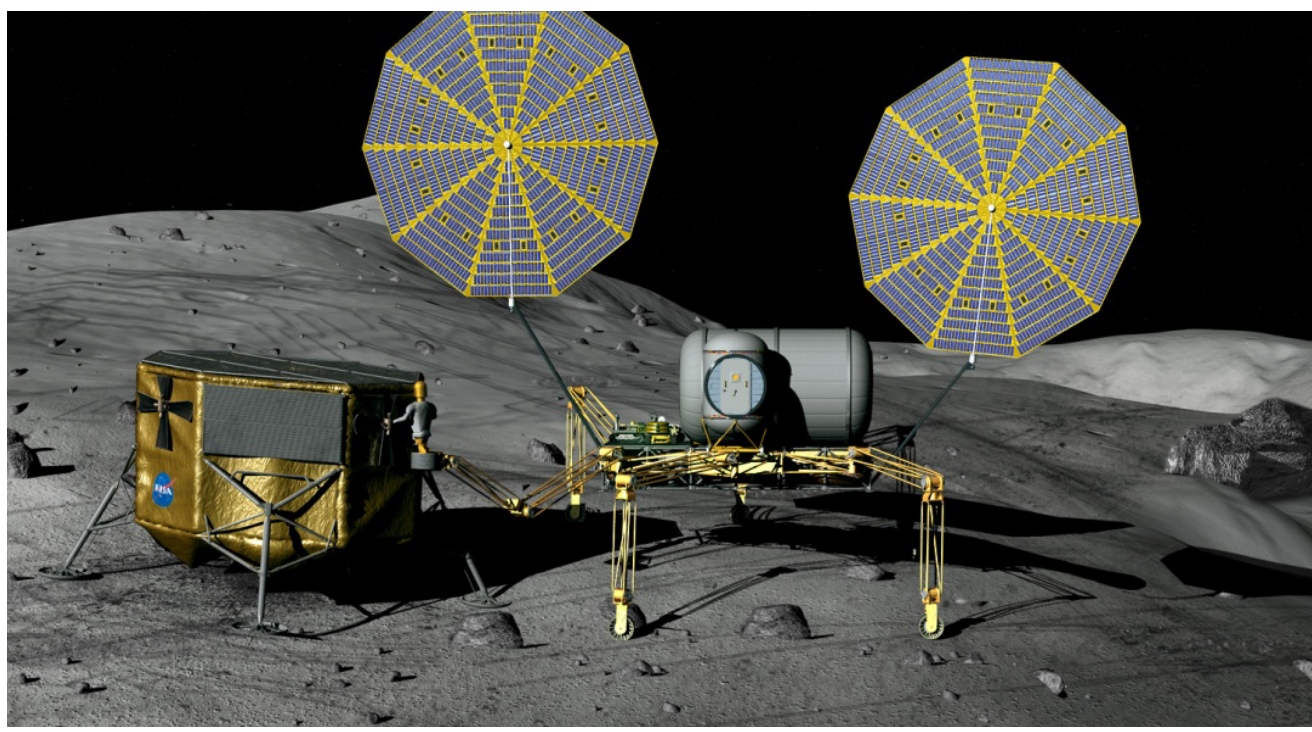

Figure 2: Robotic Scavenging. A Robotic Assistant mounted on an ATHLETE mobile robot performs hardware scavenging of the Cargo Lander. (Credit: NASA Langley Research Center, AMA Studios)

\section{E. Connection Between Scavenging and ISRU}

Since in-situ resource utilization (ISRU) affects logistics it can also be regarded as a supportability function just as scavenging is. Both non-volatile ISRU and Scavenging provide materials that may be used in repair and fabrication of surface system hardware. Scavenging of materials is seen as an early transitional form of material utilization that is eventually supplanted by non-volatile ISRU materials like metals and ceramics. Scavenging continues to play a role as long as expendable flight systems are used. As ISRU resources come on line and reusable spacecraft evolve, lunar operations transitions toward the resource independence goal outlined in the LSS Supportability Plan. ${ }^{3}$

\section{F. Embedding Scavenge-ability}

The benefits of scavenging are highly dependent on the system attributes, component properties and even the material properties. ${ }^{4}$ Scavenging, as a Supportability function, requires embedded solutions that work in concert with a set of external process technologies. Success depends on designing the hardware with embedded features and materials that renders the flight hardware reusable in the lunar environment. Hardware accessibility, configurability and commonality are attributes of reusable systems that must permeate both Altair and LSS architectures. 
Embedded technologies must be suited for scavenging processes yet still satisfy the mission needs. This includes selecting materials that are most suited for reuse in the lunar environment. Similarly, the process technologies used in scavenging must be suited to lunar environment.

\section{G. Governing Ground Rules for Scavenging Technology}

The supportability goal of achieving resource independence imposes ground rules on the architecture and scavenging in particular. These are in addition to the requirements and constraints typical of a space flight system. Meeting these ground rules assures that scavenging is consistent with the overall supportability strategy.

- Ease of Use: Low crew time and training

- Lunar Compatibility: Operates in space without special containment or enclosures

- Resource Effectiveness: Minimizes process resources and maximizes in-situ resources

- High Utility: Provides utility across an array of applications (bootstrap capability).

- Reduce Risk: Reduces or responds to risk.

\section{Reduced Logistics Dependence by Scavenging Strategy}

\section{A. Lunar Program Logistics and Support Needs}

In Earth orbit the environment for satellites and the Space Station is comparatively benign. The lunar surface has a much more intense thermal and radiation environment but systems can be designed tolerate it. Most problems can be expected when mobile hardware interacts with the environment.

The Apollo experience found that the fine abrasive lunar dust caused severe degradation in just a few operating hours. ${ }^{5}$ Lunar exploration will involve long Extra Vehicular Activity (EVA) and multi day rover sorties over rugged terrain. The risk of collision and vehicle mishaps is very high and it is likely that crews will be performing in-situ repairs. Most will be minor wear and tear repairs but major repairs are an eventuality. The fact that the architecture involves two redundant rovers is indicative of the risks.

In examining repair needs a recent study found that relatively minor hardware surface damage is a threat to system reliability and operational life. ${ }^{4}$ Damage to exposed surfaces, left untreated, can lead to much more serious downstream damage. It is particularly problematic for surfaces at the interface between moving parts. In some cases the damage to one component exposes other components and thus a problem tends to progress or propagate into a catastrophic failure or degrades operation to a point that the hardware is rendered unusable.

Hardware at risk and susceptible to hardware surface damage includes:

- Mechanical Shaft \& Bearing Failures

- Leakage of Hatchways and EVA Suits

- Degradation of Optics, Windows and Face Shields

- Degradation of Sensors and Instruments

- Malfunction of Fluid Connectors, Electrical Connectors,

- Degradation of exterior coatings, insulation of cables, and thermal protection

Dust mitigation technologies are needed to actively combat wear. In some cases damage is inevitable and a process technology that can repair the damage quickly will provide great value.

\section{Logistic Effectiveness, Reliability}

As noted earlier ISS to LSS logistics cannot expect to have a robust logistics transportation infrastructure that supplies high level assemblies on demand. Further maintenance sparing will be "open loop". That is to say that removed ORU or components cannot be returned to Earth for service. This is very wasteful and logistically ineffective unless low level repair is possible. The inability to return hardware also creates a growing reliability problem. A recent study of ISS problem reports found that at least $42 \%$ of electrical problems on ISS require a component level replacement to resolve. ${ }^{6}$ The ISS study also found that there were a significant number of problems with unknown or ambiguous root causes. Component level replacement also provides opportunities for root cause analysis. Careful examination of faulty components can isolate the root cause and new components can incorporate reliability improvements. Therefore, not only is component level repair logistically effective but it also improves system reliability over time. 


\section{Operational Constraints}

NASA prefers to avoid low level maintenance in space due to operational constraints. Due to the need to minimize crew size, the time available for hands-on maintenance and related operations is very limited. Crews are trained for specific mission roles and system maintenance is regarded as a secondary role. Examination of ISS crew training shows that the maintenance training is not sufficient to allow crews to acquire the knowledge and dexterity skills to be effective repair technicians. Considering that lunar surface operations are expected to involve more repair actions than ISS, NASA will need to consider reprioritization of its crew training. However, because the lunar crew size is limited to four people there will be additional pressure to minimize crew time available for maintenance. The only practical solution is to let ground crews assist flight crews by performing maintenance via tele-operated robots.

\section{B. Scavenging as a Path Toward Logistics Independence}

As noted earlier, scavenging is included in the Lunar Surface Systems supportability plans and in a related technology roadmap. They outlined a supportability strategy that worked toward achieving nearly full logistics independence from Earth. The global intent is to develop and demonstrate capabilities that will enable explorers of Mars to safely operate without depending on Earth. The additional benefit is that it also reduces the lunar program costs.

\section{The Supportability Strategy:}

- Migrate from Earth Logistics Dependence toward 100\% Logistics Independence

- Design systems minimize imported logistics

- Maximize use of available resources (Scavenge, Recycle, ISRU)

- Demonstrate resource independence that is essential to Mars missions

Early benefits of scavenging flight hardware:

- Recovering and preserving high value flight hardware.

- Flight hardware effectively becomes payload and thus expands payload capacity.

- Reduces the support cost by reducing the need to launch logistics spares.

- Scavenging spares is more responsive to immediate needs.

Long term benefits:

- Material scavenging and fabrication serves as a precursor to exploiting non-volatile in-situ resources.

- Scavenged hardware can be used in building a lunar infrastructure 


\section{Scavenging at Various Levels of Integration}

Scavenging can occur at various levels from highly integrated system modules to subassemblies and individual components. The lowest level involves scavenging basic materials to be used in repair and fabrication. For assemblies and components, commonality expands the number of options for exploiting spent flight hardware for spares or new applications and improves supportability.

\section{A. Scavenging Operations}

The following table indicates the order of preference for spare hardware. ${ }^{7}$ Scavenged hardware from spent flight systems may have various levels of readiness. A pristine spare from logistics is the preferred for maximum reliability and confidence that is ready to use. Lower levels of readiness imply more operations and equipment are needed to upgrade the hardware to serve as an acceptable spare.

Table 2. Categorizing Spares and Relative Readiness

\begin{tabular}{|l|c|l|}
\hline \multicolumn{1}{|c|}{ Hardware Condition } & Readiness & \multicolumn{1}{|c|}{ Comments } \\
\hline Pristine spare & A & $\begin{array}{l}\text { Ready to use with little, if any, additional checkout and } \\
\text { processing. }\end{array}$ \\
\hline $\begin{array}{l}\text { Spare Scavenged from } \\
\text { intact flight system and } \\
\text { checked out as good }\end{array}$ & B & $\begin{array}{l}\text { Hardware can be checked by donor system and internal "built in } \\
\text { tests". The risk of damage during scavenge processing reduces } \\
\text { readiness and may require additional inspections to be used as an } \\
\text { acceptable spare. }\end{array}$ \\
\hline $\begin{array}{l}\text { Scavenged Spare from } \\
\text { damaged system or system } \\
\text { without checkout }\end{array}$ & C & $\begin{array}{l}\text { Hardware that cannot be checked out by the donor system or may } \\
\text { be from a damaged system. Accepting this hardware as a spare } \\
\text { will require external equipment and checkout operations. }\end{array}$ \\
\hline $\begin{array}{l}\text { Scavenged Spare with } \\
\text { known fault or degradation }\end{array}$ & D & $\begin{array}{l}\text { Hardware is known to have a fault that will require and in-situ } \\
\text { repair. Diagnostics, de-integration, repair followed by integration } \\
\text { and test will be needed to make this an acceptable spare. }\end{array}$ \\
\hline
\end{tabular}

The process activity diagram, shown in Figure 3, is arranged as "swim lanes" where each lane represents an entity responsible for providing the specific functions or activities. The chart below was used in the Constellation Program: Common Avionics and Software Operational Concept Study. ${ }^{7}$

Swim Lane Assignments:

- Remote Earth Support Operations: This involves Earth based tele-operation crews that are controlling the processes remotely. Note that all activity decisions occur in that lane.

- Crew/Robotics: This involves the crew or robotic elements that will handle the hardware and perform scavenging processing. The crew or robots also handle the retrieval of tools and process equipment from LSS Logistics and return these to logistics when complete.

- Vehicle Systems: This may be either the flight vehicle such as Altair or it may be other LSS elements such as mobility equipment or habitat. They provide active self-test functions that can be used to aid the scavenging and installation processes.

- LSS Logistics: Provides materials, tools and equipment in support of a repair or scavenging operation. It also provides storage and workspace to perform tasks away from the vehicle. The logistics element may provide a protective environment. 


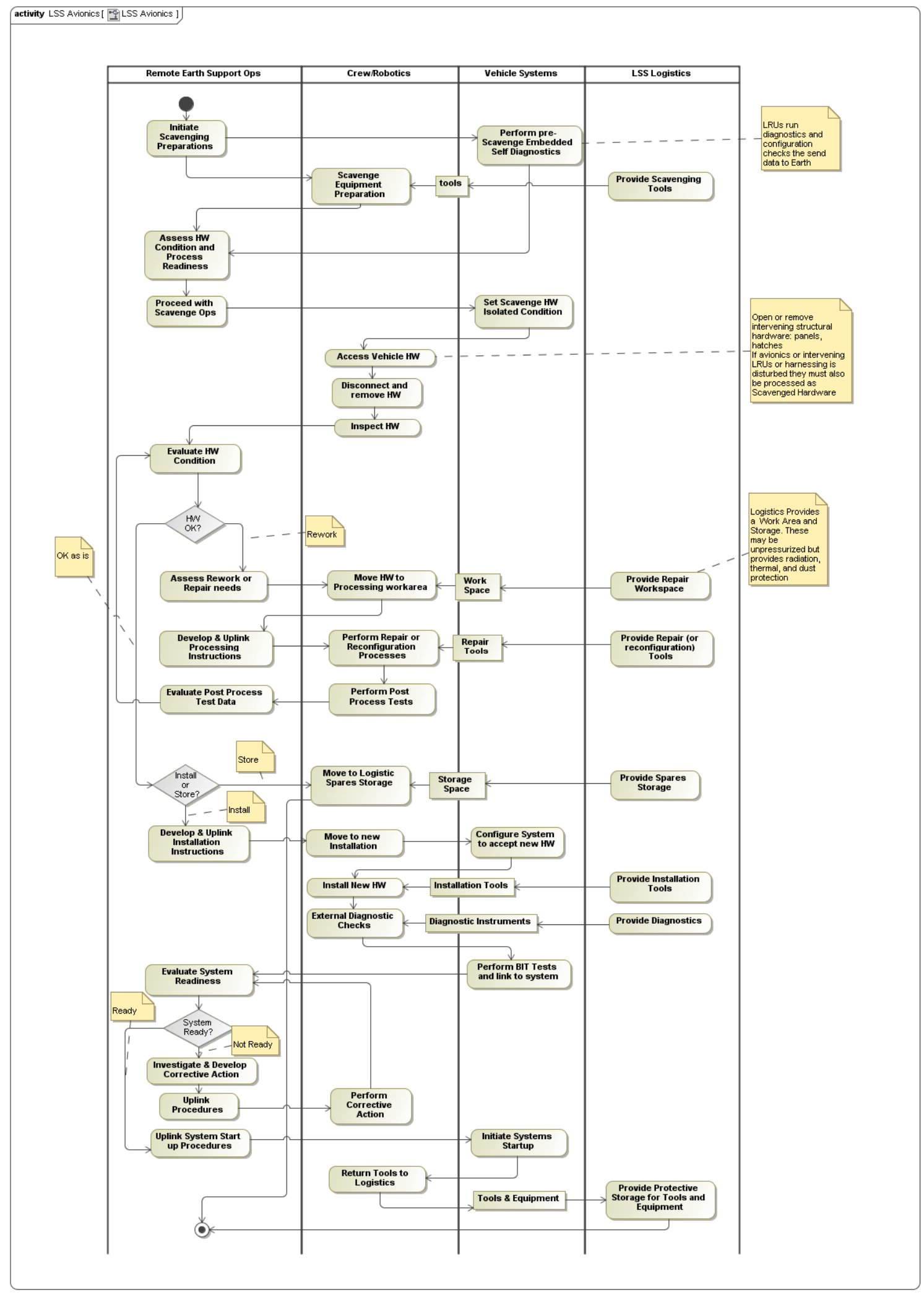

Figure 3: Scavenging and Reuse Process "swim lanes". (R. Oeftering) 
The lanes show the individual tasks in a generic scavenging process where hardware is retrieved from the source vehicle. The end application may use the hardware as a replacement spare or as an element in a new application. This activity diagram is consistent with scavenging a high level Lunar Replacement Unit (LRU).

Note that the flow accommodates hardware repairs and reconfiguration as needed to complete the application. The tasks allocated to LSS Logistics reveals that logistics does more than simply store items; it also must manage tools, equipment and provide workspace to perform repair or reconfiguration tasks. The vehicle also has an active role in the process, it provides pre-scavenge diagnostics and hardware isolation at the beginning of the process. At the end of the process, it provides self-testing and reconfigures the vehicle to accommodate the new hardware. Lower level diagrams will include the resources provided by communications, command and data handling, and electrical power subsystems.

\section{B. Scavenging Modular Assemblies}

Complete systems may be scavenged but the hardware would likely be removed as subsystem modules. The vehicle would likely use the same ORU approach as the Space Station. In this case Lunar Replacement Unit (LRU) would be designed to be easily acquired, checked-out and reused. The primary application for all scavenged hardware is to serve as spares. Spares may be stored as LRU assemblies. If a particular subassembly or component is prone to frequent failures then it should be removed from the LRU and stored separately to minimize downstream repair time. For example, power supplies and power modulators like motor controllers are most prone to failure and replacement and thus should be scavenged and stored at that level. ${ }^{6}$

An inventory of spares can be filled with a few lander flights and eventually a substantial hardware surplus will arise. At that point it becomes practical to reuse hardware in new applications. Reuse in new applications will require a great deal of commonality between systems. A recent avionics study determined that commonality between the Altair lander and Lunar Surface Systems is feasible. To succeed, however, it will be necessary to impose a high degree of commonality in the design stage. ${ }^{7}$ Carefully adhering to a common set of equipment will make it easier to reuse flight hardware in expanding the lunar architecture.

Effective reuse of flight hardware will depend on ease of access and ease of reintegration. The modularity provided at the LRU level must also be applied at lower levels. A new satellite avionics architecture has been evolving in the last decade that is very applicable to this issue. The Air Force Research Lab (AFRL) has been developing the Plug-n-Play Satellite (PnP) technology. ${ }^{8}$ This technology involves an avionics and structural architecture that is intended to enable the Air Force to integrate and launch satellites in only 6 days. PnP architecture specifically addresses the integration complexity and accessibility issues that normally impede rapid deployment.

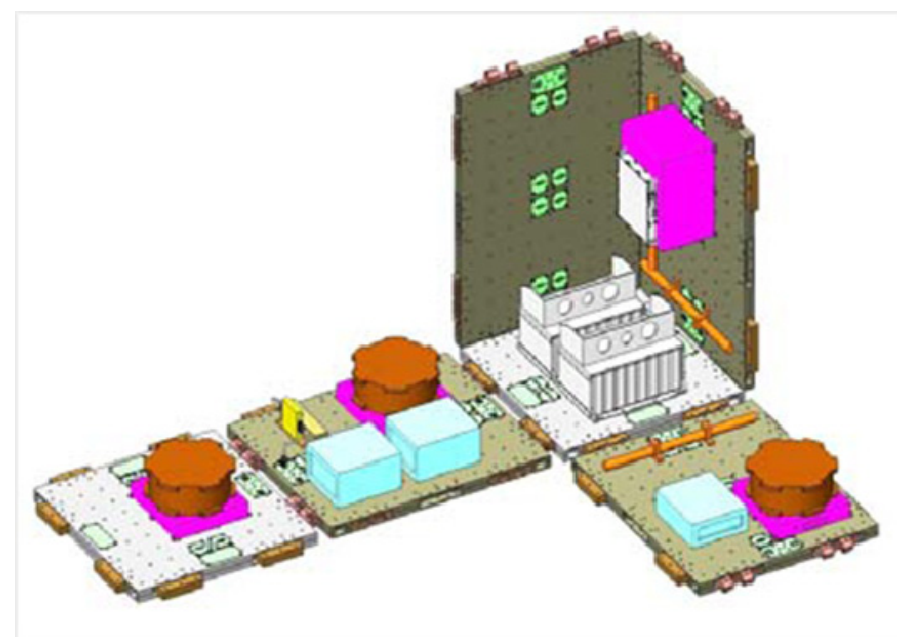

Figure 4: Plug n Play Satellite. PnP avionics provides for rapid access and simplifies hardware integration. This approach will be highly useful for lunar scavenging (Credit: Air Force Research Lab) 
This approach permits rapid access yet accommodates a wide array of instruments and avionics combinations. The PnP approach employs highly accessible enclosure assemblies with hinged unfold-able structure. The walls can flatten out to provide access without disabling the systems. The avionics employ a self organizing data network system in conjunction with smart transducer technology with embedded electronic data sheets that tell the network what the device is and what its data and power needs are. Further, it employs a power over network approach that can power small assemblies without additional power supplies. The Plug and Play avionics approach is very attractive for the reuse of lunar systems. It provides rapid access, minimizes violation of system integrity, and supports rapid reconfiguration and reintegration. Further, $\mathrm{PnP}$ features provide electrical, mechanical and structural flexibility essential to successful maintenance and scavenging.

\section{Scavenging Components}

As noted in the introduction, it is not uncommon for a major system assembly to be disabled by a single component. In the LRU approach the crew replaces a larger module primarily to return the system to full function as soon as possible. Ultimately the removed unit is repaired by a component level replacement. Component level scavenging provides a source of component replacements. Since the rate of unit faults is expected to vary system to system some LRU level replacement may be frequent while others are rare. This means that systems with frequent faults may run short of scavenged spare units while other systems have a surplus of spares.

If various systems use common components then scavenging at the component level allows the program to redistribute components to meet maintenance needs. Component level scavenging requires component repair techniques. A lunar outpost will need to be equipped to support component replacement. Further, the hardware will need to be designed to make access easy and repair as simple as possible. Component level scavenging provides additional flexibility for reconfiguring hardware for secondary purposes. The users can mix and match components from varied sources to create custom units. For electronic systems, this flexibility will be possible if the assemblies follow the same design principals as the Plug and Play Satellite program.

Altair landers provide a substantial mass in structural components. The tubular space frame construction is particularly flexible and can be reworked in to wide array of infrastructure elements. Second in mass only to structures, the lander propulsion system provides thousands of kilograms of large pressure tanks and fluid lines valves and rocket engine mechanisms. These components can be reused for fluid storage, storing spares, and support ISRU applications.

Unlike electronics, mechanical components are not, by nature, reconfigurable but they can be adapted as elements of a larger assembly. Complex mechanisms are built by combining simple components like bearings, shafts, gears, wheels, pulleys, and seals, with small assemblies like motors, gear boxes, valves, electronic boards, transformers, sensors and optics. Integrating all these elements requires a custom housing to adapt them to the new application. Because position, orientation and mechanical tolerances, not to mention structural stiffness, are so important to their function it is necessary to fabricate a completely new housing.

\section{Fabrication With Scavenged Materials}

Fabrication is essential to providing a complete utilization of scavenged hardware. Fabrication implies raw materials. Eventually, ISRU technologies will provide materials extracted from lunar sources. In the interim, the material resources scavenged from landers can build a substantial portion of the infrastructure. Surplus hardware that is unsuitable for scavenging in its current state can be scavenged for its material content. Metals, ceramics, glass and polymers can be scavenged and recycled to be used as a source of repair and fabrication materials. The most useful and versatile material, by far, is metal.

To avoid the need to deliver a massive power intensive manufacturing infrastructure, only techniques compatible with the space environment will be used. Relatively simple products would be fabricated from recycled material such as the simple housings that support complex mechanisms.

A useful approach is to adopt the "vitamin technology" a concept introduced by Freitas in $1980 .{ }^{9}$ In this concept, complex high value technology (imported from Earth) is combined with abundant but simple in-situ materials. In this case however, both the high value complex assemblies and simple bulk material come from the Altair landers. The actual technologies that make this possible are discussed a following section.

\section{E. Embedding Scavenge-able Materials}

Material Scavenging depends on building the vehicle with as much scavenge-able materials as possible. $\underline{\text { In terms }}$ of ease of scavenging and reuse in varied forms, there is no substitute for metal. Alternate materials like composites of fibers and polymers provide high strength and low weight. However composite materials are not reusable and composite fabrication processes are incompatible with space. In contrast, metals can be reused multiple times. 


\section{Fabrication and Feedstock Processing Technologies}

When describing fabrication or manufacturing in space many people envision factories with the attending massive infrastructure that it implies. Such an infrastructure is not viable in many ways but the main problem is that it is simply too costly to launch, assemble and operate. Conventional manufacturing technologies are, generally, not compatible with the space environment and require special containment. Further they depend on a wide array of consumable resources, and finally they have low resource effectiveness due to significant waste they produce. The massive size implies an exorbitant payload cost. A 10,000 kg machine, such as a large production mill would cost $\$ 1$ Billion in transportation cost alone.

\section{A. Advance Space Fabrication Technology}

A number of new manufacturing technologies have evolved in the last two decades. Generally, referred to as Free Form Fabrication (FFF), these processes are capable of creating a free standing metal product from computer data without conventional tools dies or molds. The most suitable techniques exploit the high vacuum environment and produce high quality products. The techniques that employ metal particles and electron beams are the most effective and energy efficient processes.

Electron Beam technology is particularly attractive for space applications

- Space Compatible: Compatible with high vacuum, and low gravity

- Simple Dependencies: Needs only Electric Power

- Resource Effective: Little or no waste and can use a variety of material feedstock,

- Utility: Flexible, used for fabrication, heat treating, and melting or vaporizing material.

The electron beam is a clear choice for lunar processing of scavenged materials. However, the electron beam, like the laser beam and microwave beams, is an energy delivery method. It does not address the need to deliver materials accurately. Current FFF technology is only able to produce a part that appears as a rough casting. This, in turn, requires post process machining that, in turn, diminishes the effectiveness of FFF. Producing precise parts without post process finishing needs precise methods of manipulating materials.

Current FFF often relies on simple and even primitive methods of material transport. For example, the powder may be dispensed in a simple drop spreader technique. Only a portion of the material is fused to create the product and the product is eventually pulled from the powder bed and the un-fused powder is reprocessed. While adequate for Earth applications, the powder reprocessing implies additional dedicated processing equipment.

The Electron Beam Free Form Fabrication developed by NASA Langley can build up a solid product using welding wire as a feedstock. ${ }^{10}$ This process minimizes waste and reprocessing but the accuracy of the final shape is somewhat less than the powder approach. The process would be made more effective if each particle could be accurately placed. An alternative is to use processes derived from ink jet printing technology can accurately deliver each individual droplet to a pre-assigned position. An analogous approach may be developed for solid powders. To provide even greater control of material deposition requires molecular scale processes like vapor or ion based deposition. Precise control of material delivery will be a major advance in fabrication technologies.

\section{B. Metal Feedstock Generation}

Powder is a versatile "formless" feedstock that can be stored and converted into virtually any other form. Powder is often formed in a vacuum or inert atmosphere. Once melted, a metal can be converted into a powder by an Acoustic Fountain Technique. Acoustic fountains are commonly used in ultrasonic vaporizers and humidifiers. The advantage of this acoustic technique is that it does not require gas propellant or complex mechanism to produce a fine mist and it works in a vacuum. This process can be used to produce powders from scavenged metal or metal from ISRU sources. Producing droplets can be applied directly to a surface or allowed to solidify into a powder. Using an electron beam the powder feedstock can be converted into an intermediate form such as wire for electrical and structural purposes.

\section{Hybrid Fabrication Techniques}

The natural high vacuum environment in space allows NASA to consider techniques that would not otherwise be practical on Earth. For example, a large seamless single piece structure can be constructed in-situ by metal deposition onto inflated balloon-like structures. Further, relatively complex hardware can be produced by merging pre-encapsulated components and raw feedstock a series of simple steps. 


\section{Progressive Refinement Fabrication}

Progressive Refinement Fabrication combines Additive and Subtractive processes that work together in a closed loop system that corrects deposition errors along the way. Further the process progressively reduces the scale of additive processes as it approaches a predefined product envelope. By progressing from micro-scale particles to molecular scale particles, the process slowly converges on the final finished product. The intent is to dramatically improve surface accuracy and finish while eliminating post process machining. Ion implantation and sputtering may alter surface properties and apply protective coatings.

Initial Millimeter-Micrometer Scale:

- Additive Process: At this scale use Electron Beam Free Form Fabrication process with a weld feed wire the build a rough form on three dimensions. An electron beam powder melting process can provide a slightly higher resolution but only as a series of two dimensional planes.

- Subtractive Process: At this scale may use electron beam or, Laser ablation process. Beams can be used to re-melt a rough surface to smooth it out in process called "glazing".

Intermediate Micrometer-Nanometer Scale:

- Additive Process: At this scale use liquid droplet accretion for precise three dimensional control of features, or use colloidal scale droplet mists or fine powders for depositing across surfaces.

- Subtractive Process: At this scale electron beam or laser ablation, or glazing may smooth finishes. Ion etching can surface reduction and even selectively texturing or remove contamination.

Molecular Scale Finishing:

- Additive Process: Vapor or Ion (sputtering) deposition can be used to make final smooth finish and apply protective coatings. Ion Implantation can implant special additives that can harden a surface or change its electrical, chemical or optical properties

- Subtractive Process: Ion Etching can alter finish roughness to improve bonding, Focused Ion Beam (FIB) Milling can be used to cut very fine details into the surface without masking. FIB milling can produce extremely precise sharpened edges for cutting tools.

\section{Pre-encapsulated Features}

This technique minimizes or eliminates the need for post processing by incorporating pre-machined, preencapsulated parts into the product. A similar technique has been used for casting and welding and is consistent with the "Vitamin Technology" concept where small high value features are incorporated into in-situ products. This allows precision features to be added to unfinished products by pre-encapsulating them in a jacket of compatible material that protects the feature. In this case, a FFF process deposits bulk material around the prepositioned encapsulated features. The protective shell provided by pre-encapsulation may make it possible to encapsulate a complex mechanism, valves, electronic sensors, and even optical devices.

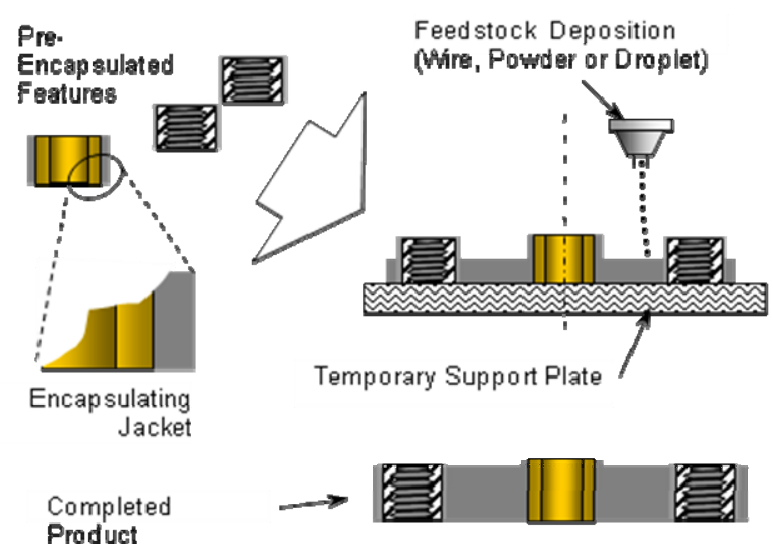

Figure 5: Free Form Fabrication incorporating Pre-Encapsulated features. (R. Oeftering) 


\section{Soft Tool Fabrication}

Another technique takes advantage of the ability to deposit a small amount of material and its small amount latent thermal energy onto a relatively low temperature soft surface. Inflated polymer structures have been rigidized by depositing aluminum vapor to make high quality reflectors and antennas. ${ }^{12}$ This process can be extended by taking the shell formed by vapor deposition and then reinforcing it by a droplet or powder accretion process. This technique may be applied to produce smooth mechanical bearing surfaces. The soft tool approach may be extended to large scale containment vessels and habitats.

\section{In-Situ Fabricated Assemblies}

Assemblies may be composed of a mix of hardware and materials from various sources including scavenged hardware, pre-encapsulated hardware, and FFF fabricated components. In the figure below, an electron beam is used to fuse a fabricated socket to a tube scavenged from a lander structure. Ion sputtering is used to apply a layer of dry lubrication prior to assembly.
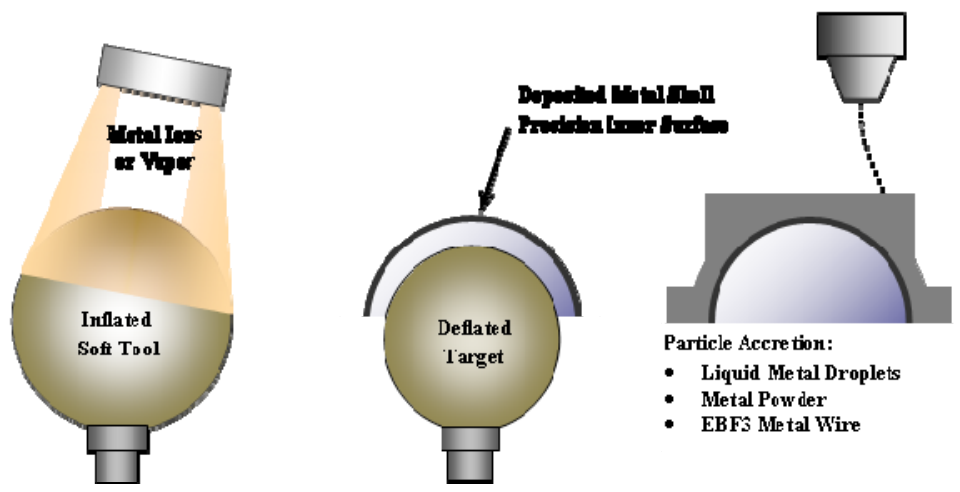

Figure 6: Soft Tool Approach. Precise shell is formed by vapor metal deposits onto an inflated sphere. The shell is then reinforces it with particle scale deposition (R. Oeftering)

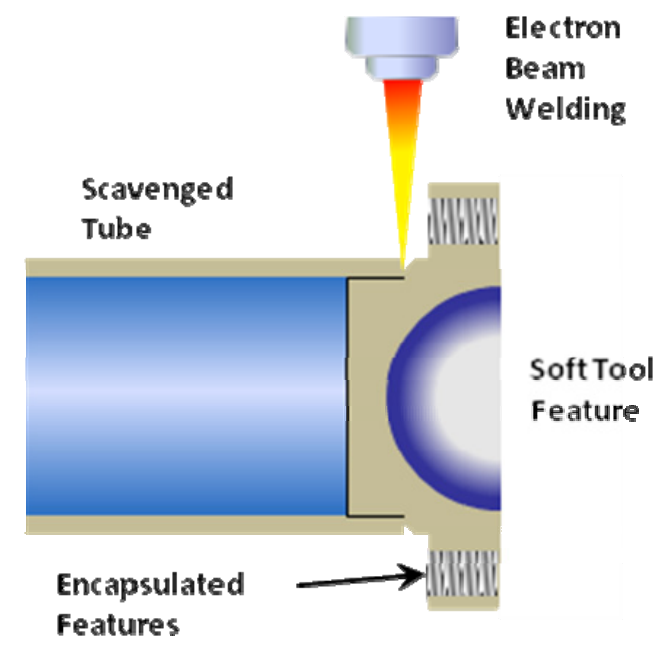

Figure 7: Fabricated Assembly. This assembly is composed of Encapsulated Features, Soft Tool Features joined with Scavenged Components. (R. Oeftering) 


\section{Soft Tool Approach to Large Structures}

The high vacuum and low gravity environment allows the "Soft Tool" approach to be extended to larger inflatable structures. Tubular structures, pressurized tanks, and pipes may be built by this technique. Lightweight inflatable polymer film bodies can be metalized by metal vapor or metal ion deposition to form a thin shell. The shell is then reinforced by additional layers of metal droplets or powder metal accretion to form a rigid self supporting structure.

The final structure may include added ribs, brackets, flanges or other features that are accreted directly to the surface or welded on. Further, special components may be added by the Pre-encapsulation methods described earlier. With careful process control it will be possible to integrate complex mechanisms like pre-encapsulated valve assemblies.

This process is very analogous to how large composite structures are built. Once complete, the inflated polymer may remain as an impermeable membrane or it may be removed as a reusable soft tool. Removal also facilitates adding internal features and if needed outfitting the interior. This method and can be employed in construction of very large seamless pressurized structures much larger and more massive than can be practically launched from Earth. Building structures this way provides a seamless construction method that could reduce the number of leaks that occur in conventional pressure vessels and cabins.

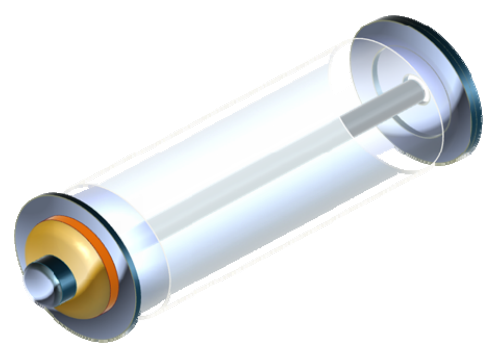

a. An inflated polymer tube is pressurized between two flanges to be used as a "soft tool".

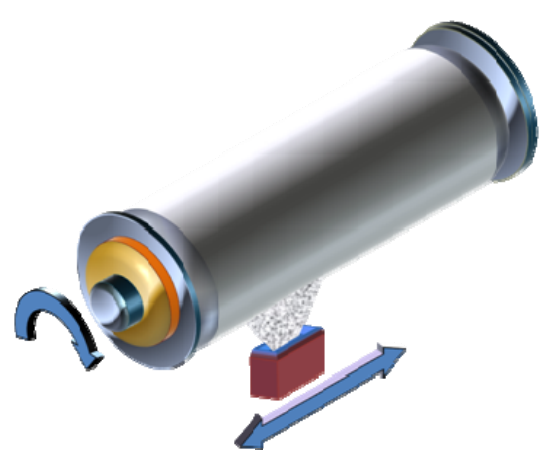

c. Once a thin metal shell has been formed reinforcing material is deposited by a droplet or powder deposition process. This deposition can merge the end flanges with the shell.

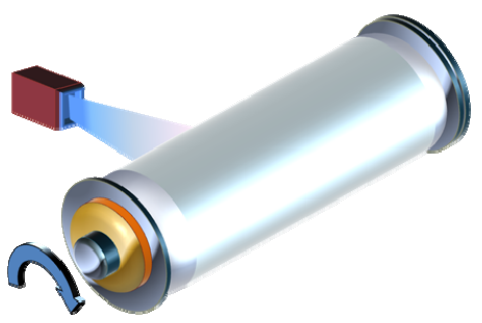

b. Polymer surface is metalized by vapor or ion sputtering deposition to form a thin shell.

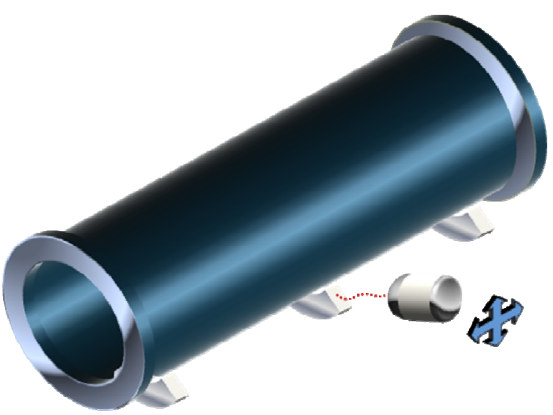

d. Once a thick reinforced shell is complete, The polymer tube is deflated. Details features like flanges brackets and supports are added by free form fabrication techniques or welding. Additional protective coatings can also be applied.

Figure 8: Building a large structure using an inflated soft tool technique. 


\section{Reuse Analysis of Altair Systems}

In the current lunar exploration architecture, every year two cargo landers and two crew landers arrive. A relatively large inventory of surplus equipment and quickly accumulates. ${ }^{13}$ With spares needs satisfied relatively early there are opportunities to diversify the applications. Expanding the lunar power, communications, robotic, logistics and ISRU infrastructure becomes next priority. Each system has unique characteristics that affect the process of scavenging and its reuse application. Some systems can provide a complete solution as is, while others must be augmented with additional hardware. In the analysis below Life Support and EVA are not included because they are Ascent Stage systems and not available for scavenging.

\section{A. Avionics}

Altair Avionic systems include Command \& Data Handling (C\&DH), Communications \& Tracking (C\&T), Guidance, Navigation \& Control (GN\&C). On the crewed sortie and outpost configured Altair the systems are split between the Ascent Module and Descent Module as shown in Table 3. Though the Cargo Lander has $1 / 2$ the total avionics mass of the Outpost Lander, its avionics are complete systems and thus a very suitable target for scavenging. ${ }^{13,14}$

Table 3: Avionics Mass Split

\begin{tabular}{|c|c|c|c|}
\hline Altair Configuration & \multicolumn{2}{|c|}{ Altair Outpost Lander } & Cargo Lander \\
\hline Module & Ascent Module & Descent Module & - \\
\hline Vehicle Avionics & $\mathbf{1 4 4}$ & $\mathbf{1 1 1}$ & $\mathbf{1 2 3}$ \\
\hline C\&DH & 79 & 72 & 75 \\
\hline C\&T & 24 & 2 & 19 \\
\hline GN\&C & 41 & 37 & 29 \\
\hline
\end{tabular}

\section{C\&DH Reuse Applications}

The digital nature of C\&DH makes it most suited as a spare since computers and network hardware are common and easily interchangeable. ${ }^{15}$ This is particularly true if a Plug-N-Play Avionics architecture is adopted. C\&DH will likely be effective in supporting many reuse applications. Both LSS and Altair utilize a network system where the main computers connect to remote interface units via network connections. For reuse in new applications most physical reconfiguration would be in these remote multiplexor (RMUX) units. Analog input and output circuits tend to be specialized, thus a unit may require reconfiguring or replacing circuit cards in these RMUX units. The reusability would be further enhanced if an IEEE 1451 Smart Transducer interface standard is used that provides a network enabled sensor system making reconfiguration easier. ${ }^{8}$

\section{C\&T Reuse Applications}

The Ascent Module has virtually all the C\&T system hardware while the DM has no significant communications and tracking except for an external EVA antenna. The Cargo lander has a complete S-Band radio communication system although it has no voice transmission. S-Band radio provides a comparatively low data rate Direct-withEarth (DWE) link. S-Band is suited for reuse as a command and telemetry link on remotely place instruments or infrastructure equipment. S-band would be a useful tool for long distance surface exploration. S-Band may be used for detecting lunar water deposits.

\section{Guidance Navigation \& Control}

Except for proximity operations (ProxOps) hardware the cargo lander GN\&C system is complete. GN\&C includes inertial measurement units, accelerometers, precision time elements, and star trackers. The instruments and controls associated with maintaining spacecraft orientation may be useful for mobile equipment. Both Outpost DM and the Cargo lander have radar. The Outpost DM however has a secondary radar and terrain hazard detection system. ${ }^{7}$ The radars may be useful for ranging distant terrain and may be altered for water detection. 


\section{B. Power}

Unlike the Orion vehicle the Altair lander does not have solar arrays. It has an enormous volume of hydrogen and oxygen that can be tapped to drive fuel cells. The power system, like the avionics, is split between the Ascent Module and Descent Module. The outpost lander has twice the power system mass as the cargo lander. This is because the AM unit provides support for the crew activities throughout flight and for one day on the lunar surface. The AM power system mass includes a large lithium battery and the power distribution control, switchgear and conductor lines. The DM power actually charges the AM battery. The DM hardware appears to be usable, as long as, propellant residuals remain. The fuel cells also produce water as a byproduct. The water line however is cut when the Ascent Module lifts off by a "guillotine" separation device and exposes the system to space. To prevent the loss of useful residuals an alternate staging disconnect will be needed.

Table 4. Power System Mass Allocation

\begin{tabular}{|c|c|c|c|}
\hline Altair Configuration & \multicolumn{2}{|c|}{ Altair Outpost Lander } & Cargo Lander \\
\hline Module & Ascent Module & Descent Module & - \\
\hline Power System & $\mathbf{1 6 6}$ & $\mathbf{2 2 4}$ & $\mathbf{1 8 6}$ \\
\hline
\end{tabular}

The Cargo Lander has a largely passive payload and aside from keeping systems warm awaiting crew arrival the vehicle is largely inactive after landing. The Cargo Lander power is a complete system similar to the Outpost DM. ${ }^{13,14}$

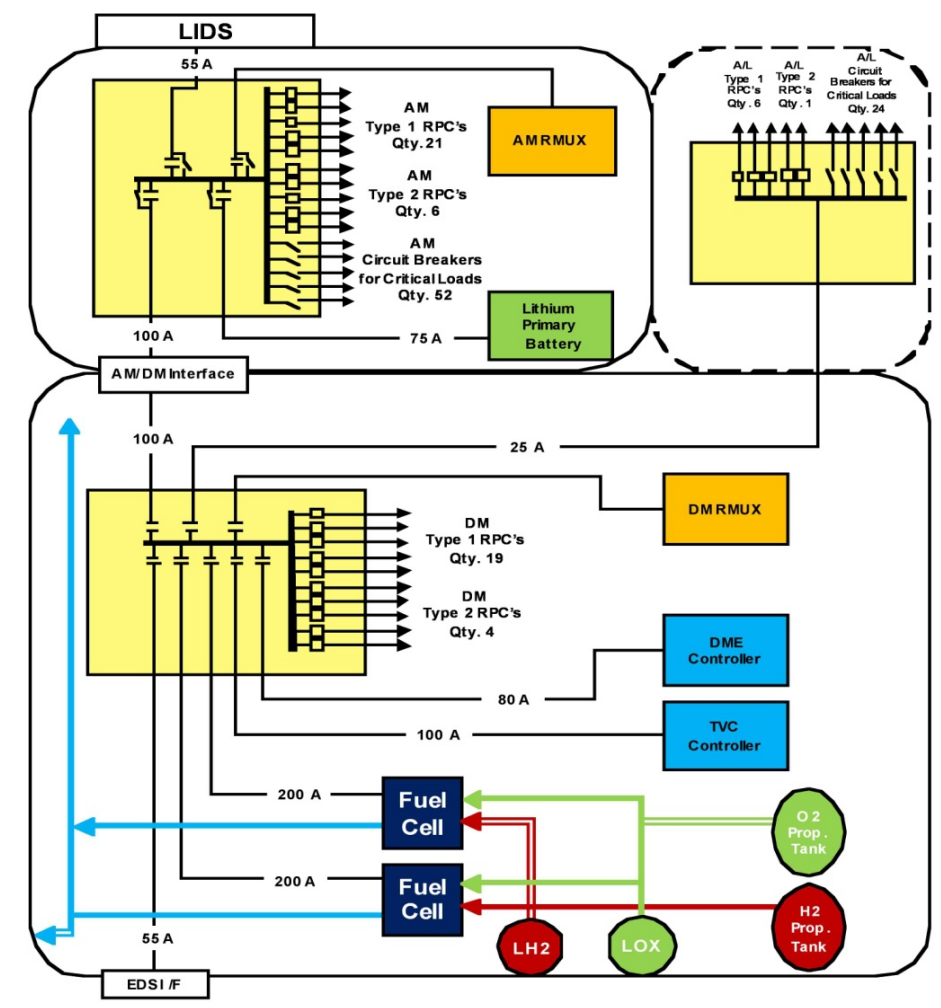

Figure 9: Altair Power System Diagram. This diagram illustrates how the powers system is split between Ascent Module and Descent Module. Note that the Air Lock Element is also shown (Credit: R. Button NASA) 


\section{Thermal Control}

Thermal control is closely linked to electric power dissipation and to the heat contribution from human crew. As in the power system, the AM thermal mass reflects the needs of the ascent phase of flight and has additional support from the DM through most phases. Once again, the cargo lander is a complete system $[13,14]$.

Table 5: Thermal Control System Mass Allocation

\begin{tabular}{|c|c|c|c|}
\hline Altair Configuration & \multicolumn{2}{|c|}{ Altair Outpost Lander } & Cargo Lander \\
\hline Module & Ascent Module & Descent Module & - \\
\hline Thermal Control & $\mathbf{2 4 8} \mathbf{~ k g}$ & $\mathbf{9 6 8} \mathbf{~ k g}$ & $\mathbf{7 9 2} \mathbf{~ k g}$ \\
\hline \# of cold plates & $\mathbf{2 4}$ & $\mathbf{9}$ & tbd \\
\hline
\end{tabular}

The thermal control system, like power, is woven throughout the vehicle architecture. But unlike power this system involves fluid lines that require extra operations to extract and store fluids. Many heat loads are connected to the system via cold plate mounts. Because of the centralized fluid system it is hard to use only part of a system for an application.

If new applications require significant power they should likewise be expected to require significant thermal control. The centralized thermal control system makes it difficult to reuse only parts of the system. If scavenging was a design requirement then a less centralized multiple path system might emerge. The size of the system however, makes it possible to reuse it as part of the cooling loop for a solar dynamic or nuclear power system. The system components could also be used as spares for the habitat thermal control system.

\section{Descent Module Propulsion}

The Outpost DM and Cargo Lander's main propulsion systems are identical. Propulsion is second only to structures in hardware mass. The system is complete regardless of configuration. The design is based on a single RL-10 engine system with nearly 50 year legacy and is considered to be perhaps the most elegant rocket engine in terms simplicity, reliability, and performance. ${ }^{13,14}$

Table 6: Propulsion System Mass Allocation

\begin{tabular}{|c|c|c|c|}
\hline Altair Configuration & \multicolumn{2}{|c|}{ Altair Outpost Lander } & Cargo Lander \\
\hline Module & Ascent Module & Descent Module & - \\
\hline AM Main Propulsion & $\mathbf{5 4 7}$ & - & - \\
\hline DM Main Propulsion & - & $\mathbf{2 5 9 3}$ & $\mathbf{2 5 6 6}$ \\
\hline Decent Engine & & 204 & 215 \\
\hline Vector Control & & 40 & 20 \\
\hline Prop Feed Sys & & 713 & 776 \\
\hline Fuel/Ox Tanks & & 1117 & 1008 \\
\hline He Press Control & & 425 & 453 \\
\hline Prop Instruments & & 24 & 24 \\
\hline Prop Thermal & & 70 & 70 \\
\hline
\end{tabular}

The Outpost Lander's AM and DM stages have two separate propulsion systems that use two completely different propellants and thus their hardware is completely incompatible. DM propulsion system has no application as direct spare for Altair or for Lunar Surface Systems. There are, however, downstream applications for the complete system when ISRU derived propellants become available. The propellant tanks and propellant feed system combined make up $70 \%$ of the propulsion system weight. This system can be scavenged intact with instruments and thermal insulation. By removing the engine the propellant system could serve as a storage system for ISRU materials and volatile fluids. The propellant system hardware may be combined with additional pumps and compressors to serves as a cryogenic storage facility. The initial core can be expanded by adding propellant systems from successive landers. 


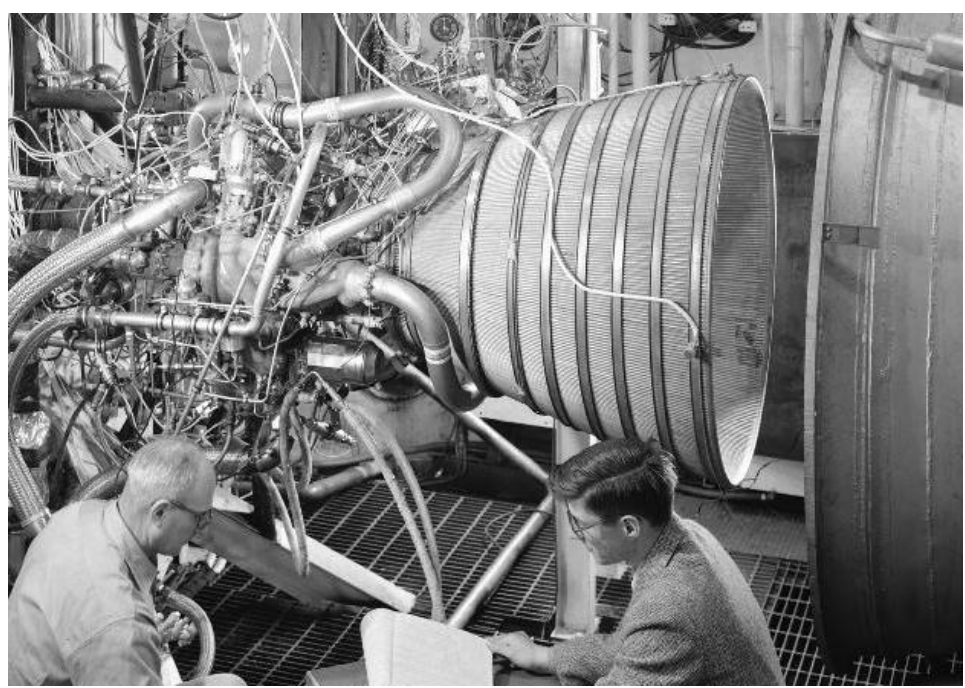

Figure 10: Pratt \& Whitney RL-10 Rocket Engine at NASA Glenn Research Center. The engine has many useful components. The main thrust chamber acts as a heat exchanger. (NASA Photo)

The tanks can be scavenged individually to support general purpose storage or robotic services bays. The large tanks can be sectioned to provide sheet or plate stock for building infrastructure. For example, a tank sliced into segments can be used for regolith "bulldozer" blades or modified into excavation buckets. This will be most effective if the tanks are constructed from metal rather than composite materials. The engine itself could be reused as part of a solar dynamic power system. The engine thrust chamber is actually an array of stainless steel tubes that conducts combustion heat and generates hydrogen vapor to drive the turbine. A thrust chamber could be configured to act as a very basic solar receiver to boil water and generate steam to drive a turbine power generator.

\section{E. Reaction Control System}

Ascent Module Reaction Control System (AM RCS) is a pressure-fed, monomethylhydrazine (MMH) and nitrogen tetroxide (NTO) system. This system shares its propellant supply with the AM main propulsion unit. The AM RCS is composed of four pods with five thrusters each including two at $890 \mathrm{~N}\left(200 \mathrm{lb}_{\mathrm{f}}\right)$, one at $445 \mathrm{~N}\left(100 \mathrm{lb}_{\mathrm{f}}\right)$, and two at $111 \mathrm{~N}\left(25 \mathrm{lb}_{\mathrm{f}}\right)$. AM main propulsion the propellant feed system hardware weight covers the AM RCS as well.

The Descent Module Reaction Control Systems for the Outpost and Cargo Landers are the same. Like the AM it is also a pressure fed MMH/NTO propellant system. All RCS thrusters are fed by a single set of propellant tanks. The DM RCS thrusters provide $445 \mathrm{~N}\left(100 \mathrm{lb}_{\mathrm{f}}\right)$ of thrust each. They are arranged in four unit pods with a pod in each quadrant for a total of 16 engines [13, 14]. For spares application the DM thrusters could serve as a spares for the $100 \mathrm{lb}_{\mathrm{f}}$ units on the AM.

Table 7: Reaction Control System Mass Allocation

\begin{tabular}{|c|c|c|c|}
\hline Altair Configuration & \multicolumn{2}{|c|}{ Altair Outpost Lander } & Cargo Lander \\
\hline Module & Ascent Module & Descent Module & - \\
\hline AM RCS & $\mathbf{1 0 3}$ & & \\
\hline DM RCS & - & $\mathbf{3 2 2}$ & $\mathbf{3 2 2}$ \\
\hline RCS Feed Sys & & 21 & 21 \\
\hline RCS Tanks & & 31 & 31 \\
\hline RCS Engines (16 units) & & 231 & 231 \\
\hline RCS Press & & 21 & 18 \\
\hline RCS Instru & & 18 & 18 \\
\hline
\end{tabular}


The DM RCS system scavenged as a whole could find useful application as a "Propulsive Hopper". Note that in $1 / 6 \mathrm{~g}$ a single $100 \mathrm{lb}$ force thruster could hover a roughly $600 \mathrm{lb}$ vehicle. Two $100 \mathrm{lb}_{\mathrm{f}}$ thrusters produce enough thrust to put a $600 \mathrm{lb}$ vehicle in lunar orbit. The reaction control system would be ideal for a short range robotic hopper if the thrusters could be reconfigured into cluster of engines. Note that the Mars Viking mission used a cluster of RCS motors for landing.

Robotic propulsive hoppers could be constructed and used to land instruments in remote or difficult to access areas. Hoppers could be used to deploy robots in deep craters to investigate ice deposits, deploy volatile resource extraction equipment, and even assist in delivering power and communications lines.

There are several problems that impede reuse.

- Highly toxic propellants that could contaminate Outpost hardware and EVA suits.

- There is no in-situ source for these propellants.

- Engines are un-cooled and have short operating duty cycle.

A substantial inventory of thrusters will accumulate by scavenging the RCS systems from landers. After 10 missions no less than 160 thrusters are available. A system that used LOX/LH2 or LOX/LCH4 propellants rather than MMH/NTO would make the thrusters more reusable and could exploit the cryo-propellant residuals and eventually in situ propellants.

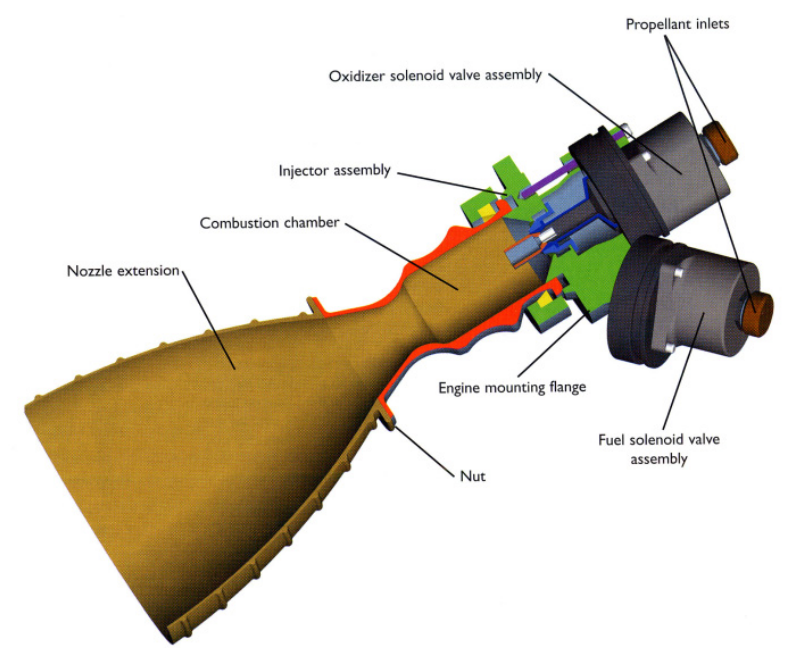

Figure 11: Reaction Control System Thruster. (NASA Constellation Image)

\section{F. Scavenged Structures}

Structural design between the Ascent and Descent Module is dramatically different. The AM is a pressurized cabin constructed of composites while the DM is a tubular space frame construction.

Table 8: Structures Mass Allocation

\begin{tabular}{|c|c|c|c|}
\hline Altair Configuration & \multicolumn{2}{|c|}{ Altair Outpost Lander } & Cargo Lander \\
\hline Module & Ascent Module & Descent Module & - \\
\hline Structures & $\mathbf{8 5 8}$ & $\mathbf{3 3 9 3}$ & $\mathbf{3 1 3 0}$ \\
\hline
\end{tabular}

The Descent Module and Cargo Lander tubular frame design may be composed of a combination of metal and composite elements. A tubular space frame is perhaps the most versatile structure known and can be scavenged and reused in a wide variety of external structural applications often with no modification. Further, the frame is substantially overbuilt for lunar applications because it is designed to tolerate the high-g acceleration and vibration loads of Earth launch. 
Structure applications include:

- Support Frames for Solar Power Arrays

- ISRU material acquisition and machinery support.

- Robot extensions for lunar bulldozer, cranes and drag-lines for regolith processing.

- Power and communication transmission support towers

- Supports struts for facilities and habitats

- Components for large scale robotic equipment.

\section{Building a Cis-Lunar Infrastructure}

Each scenario below describes one of many potential scenarios. The concepts are notional and the intent is to show how the Altair lander hardware can be scavenged and reused with the process technologies described earlier.

The scenarios have the same central goal of building an in-situ resource infrastructure capable of generating power, extracting and processing resources, including lunar water and exporting propellants to supply a cis-lunar space infrastructure. The assumption is that the initial activity takes place in a lunar polar highland area for solar power and communications access and constructs an infrastructure that connects to the polar craters for access to volatile resources. These scenarios will illustrate how scavenging at various levels contributes to the result.

\section{A. Energy Resource Scenario}

This scenario involves building the Lunar Power Infrastructure from scavenged hardware and materials. The objective is to scavenge Altair systems and construct a viable Solar Dynamic Power Generation System. The primary systems contributing are Propulsion, Power, Thermal Control, Avionics, and Structures.

The scenario is based on the recognition that a liquid rocket engine is a thermodynamic system. In this case, the RL-10 engine is well suited because it uses an expander thermal cycle that captures heat from the combustion chamber and drives the turbo machinery that pumps the propellants. The RL-10 engine turbine assembly is capable of over $800 \mathrm{hp}$ which is roughly equivalent to 600,000 watts of power. In this scenario only a small fraction of that capacity is used based on the limitations of solar reflectors and the cold side of the thermal system. However, even de-rated to $10 \%$ of capacity the turbines could still produce 60,000 watts of power.

The working fluid will be water and the thrust chamber will be used as a solar receiver to create steam that drives the turbine. This turbine, in turn, drives a power generator and indirectly powers a water pump to return condensed steam. The steam is condensed by a heat exchanger that couples the steam system with the cooling system scavenged from the landers TCS. As illustrated in Figure 12, another RL-10 thrust chamber and a surplus propellant tank are combined to serve as a heat exchanger. The thrust chamber tubes are the steam side while a water fill propellant tank serves as the cold side. The TCS radiators provide the final heat rejection. The thermal control radiators are placed in an area shielded from the sun. Alternatively, the heated fluid may be pumped to a system of buried tanks serving as thermal bunkers. The bunkers create a thermal reservoir used to keep the working fluids from freezing and damaging the systems during times of eclipse.

Solar energy is delivered by an array of mirror like reflectors. The reflectors will be a metal foil or metalized polymer suspended in frame of scavenged structural tubes. The metalized polymer film is scavenged from the landers multi-layer insulation system. The foil may be rigidized into metal sheets by metal droplets or powder deposition process. The reflector array may be arranged as a circular ring pattern to track the sun during the lunar day. In this arrangement only a section of the reflector array is illuminated. The very low polar sun angle may require portions of the array to be folded down while others are elevated for best sunlight capture. The receiver is in a central location and rotates toward the area of highest reflected intensity.

Although certain sites have a very high percentage of sunlight per month, such as Mt. Malapert, they may not be close to the volatile sites. Thus it may be necessary to create multiple sites linked as a power network to maximize monthly power coverage. 


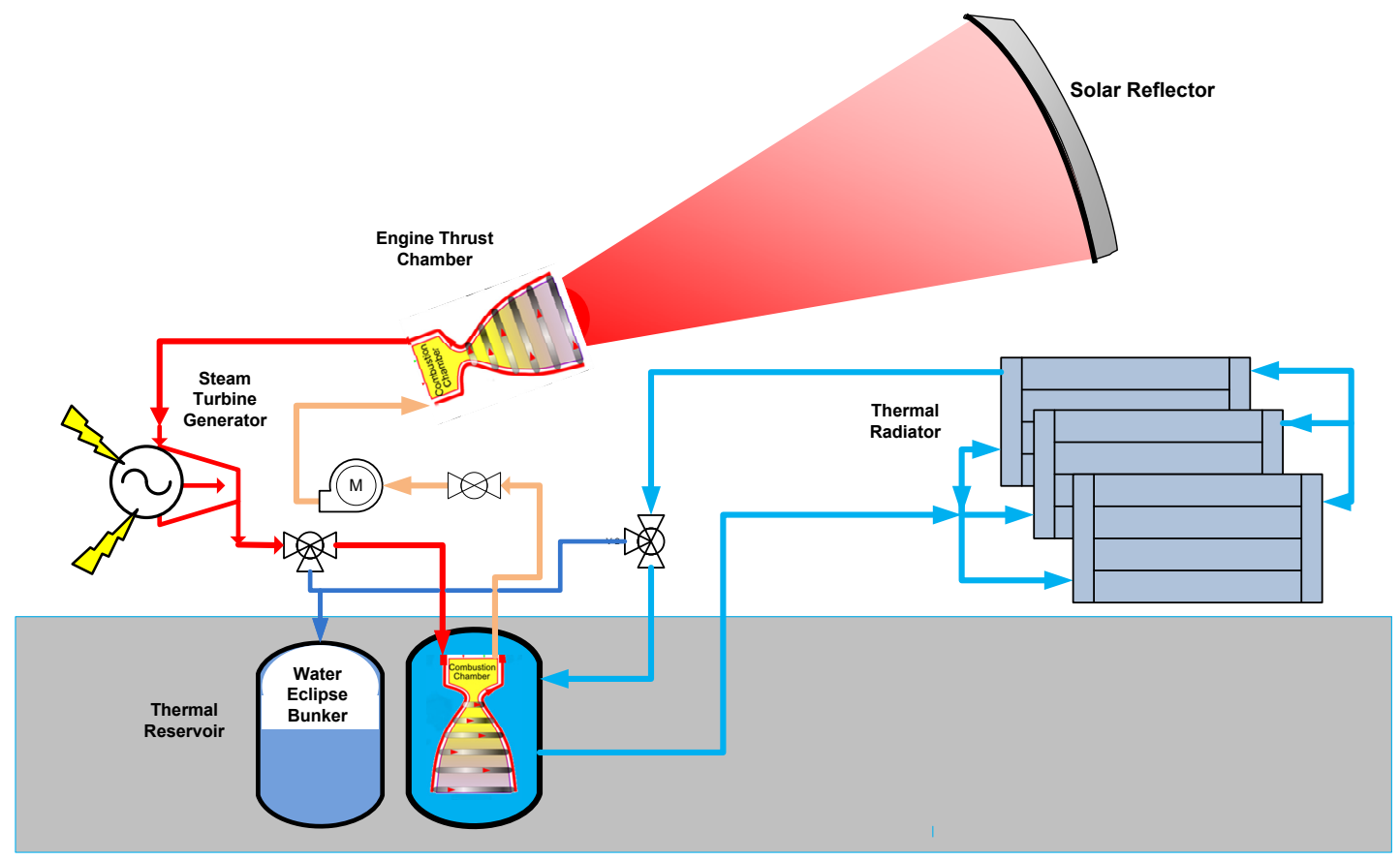

Figure 12: Illustration of a power system composed of scavenged lander system hardware. (R. Oeftering)

Energy storage may take a number of forms. However, fully exploiting local resources will involve water. Electric power would be used to electrolyze water into hydrogen and oxygen that in turn serves a source for fuel cells. Fuel cells are scavenged from the descent module and cargo landers. This approach provides power for eclipse periods and augments the main power system. The main end users are the volatile and non-volatile resources processes and fabrication processes.

A number of factors that make this application possible:

- The thrust chamber is actually a heat exchanger and constructed from stainless steel.

- Turbine runs on hydrogen vapor but is tested with steam.

- Oxidizer pump is tested with water.

- The thrust chamber can be separated from injector creating a closed system.

- The engine has a gimbal mount and vectoring actuators

- Water is available as a propellant residual or from lunar sources

Hardware from multiple Altair landers are scavenged and modified for this application.

- The injector assembly is removed from the thrust chamber

- Propulsion system valves and flow regulators are reused

- The turbo-machinery is removed and turbine separated from the oxidizer pump

- The turbine is coupled with an electric generator.

- The oxidizer pump is coupled with a regulated drive motor to serve as water pump.

- A propellant tank are modified to store water and to serve as heat exchangers

- An engine is mounted inside the tank

- Propulsion system ducts and valves are reused in the water system

- Multiple Thermal Control Systems are used with minor modifications

- The thermal control system is coupled with tank-heat exchanger

- Tanks are buried in regolith as thermal bunkers

- Multiple Altair power systems (regulators, switch gear, cables) are used to manage the power.

- C\&DH electronics is configured as system mangers interacting with subsystem controllers.

- C\&T electronics provides wireless links to habitats and direct to Earth monitors. 
- GN\&C provides sun tracking and reflector array pointing

- Structures provide support for arrays and many individual elements in the system.

- Scavenged mechanisms are used for reflector array pointing, tracking and folding.

\section{B. Power Transmission System}

Power could be transmitted via microwave or by metal conductors. In either case, support towers will be needed. Microwave systems still needs towers for line of site over high terrain. These towers can also serve as communications antenna links. Tower structures would take advantage of the many tubular structural elements in the lander assembly. One lander is estimated to have enough structure to erect a tower in the range of $15 \mathrm{~m}$ to $30 \mathrm{~m}$ high depending on the load it must support.

For power conduction, an aluminum conductor cable of \#2 gauge $100 \mathrm{amp}$ current capacity would weigh roughly $83 \mathrm{~kg} / \mathrm{km}$. Two conductors spanning a total length of $4 \mathrm{~km}$ to reach into a deep crater is $332 \mathrm{~kg}{ }^{17}$ If $100 \mathrm{amp}$ aluminum power cables ( 2 conductors) was run from solar arrays on Mt Malapert to a crater with volatiles $100 \mathrm{~km}$ away it will likely weigh over 16.6 metric tons. However, if an aluminum wire fabrication system was established and if 3 metric tons of aluminum is scavenged from each lander the power cable lines could be built with material scavenged from 5 to 6 landers.

\section{Volatile Resource Scenario}

The availability of water as ice in the deep craters around the poles is one of the main reasons for visiting the lunar poles. It cannot be overstated how important that resource is for the future of human space mobility. Water can be broken down into $\mathrm{O}_{2}$ and $\mathrm{H}_{2}$ by simple hydrolysis and used as propellants or for storing energy in fuel cells. It will profoundly change the nature of exploration and open space beyond earth orbit. Recent missions including the Lunar Reconnaissance Orbiter (LRO) mission and related Lunar Crater Observation and Sensing Satellite (LCROSS) continue to build evidence of vast quantities of lunar water.

This scenario builds an infrastructure for the acquisition and processing of the moon's most valuable resource, specifically, the water in polar craters. With water in substantial concentrations at the surface extraction may be as simple as applying heat and collecting vapor. The main consumable is electric power.

Due to the high vacuum, the vapor molecules emanated from the ground, travel outward until stopped by any cold condensing surface and freeze. In the extremely cold environment (less than $100 \mathrm{~K}$ ) all that is needed is a cold surface for the vapor to collect on. The collection could be performed by simply suspending a thin film tent over the site. The collection of frost could continue to build up into thick deposits. To improve collection efficiency a labyrinth of thin sheets are hung inside the tent arranged around the vapor emission site. When the collector panels have accumulated enough ice the panels are removed to be melted inside a heated chamber where the liquid water is collected. The panels are then reinstalled at the collection site.

If water is plentiful and processing proves to be relatively simple, then the remaining issue is getting access to the water and connecting the power, communications and transport infrastructure. Moving into and out of the craters safely and efficiently is the main challenge. There are two methods suggested:

1. Use a suspended cableway system to move equipment and ice in and out of the site. This option also provides a way to deliver electric power.

2. Use a propulsive hopper particularly in the early stages of deployment.

\section{Cable transport system}

A mechanical cable system can be used to transport materials and equipment between sites. Since power transmission by conductors or by microwave will still need support towers a cableway system would share facilities. Cableway systems have long been used when roadways or rails where impractical due to terrain. They have also been used when traffic is too low to justify the cost of a bridge or roadway. Unlike power transmission, cableways need not extend for the entire distance between Mt, Malapert and the craters. The system may be a mix of cleared paths in flat terrain and cableways over rough terrain. This would be very useful in moving equipment into craters and lifting water ice out of craters.

A mechanical cable system can be strung in parallel with power that, once erected, becomes a very efficient means of transportation over rough terrain. For mechanical cable, Kevlar rope is known to maintain strength and flexibility at cryogenic temperatures. A $3 / 8$ " Kevlar rope weighs $84 \mathrm{~kg} / \mathrm{km}$ or $336 \mathrm{~kg}$ for a $4 \mathrm{~km}$ length. ${ }^{18}$ An alternative is to fabricate a metal cable from in situ iron. Iron is expected to be the easiest metal to extract. Iron would need to be alloyed into a suitable steel for cable (or possibly chain) using imported alloying materials like chrome. 
Pulley wheels and winch mechanisms for handling cable have wide utility in general. Pulley shafts and main bearings would be imported but wheels could be constructed from portions of surplus propellant tanks, particularly, if they had flanged heads. A tank that has reversible head flanges could be reconfigured into a wheel particularly if the head had a small central flange that could then support a bearing installation. This is an example of how the flight hardware design can embed features that enhance reusability.

\section{Propulsive Hopper}

Although processing in-situ water resources may be best served by an efficient cable based transport system, it is a significant infrastructure to build and will take time to evolve. In the early stages, the need is for the ability to get into the dark crater and back out without the hazards of climbing the yet unknown terrain. Recent LRO instruments have determined that the polar craters have relatively steep slopes. ${ }^{16}$ Like a helicopter, a propulsive hopper can move into the area in a matter of seconds and hover above hazards until a suitable site is found.

As discussed earlier it may be possible to construct a hopper from scavenged RCS systems. There is an abundance of surplus RCS thrusters that could be configured as a lunar hopper. The main problem is the type of propellant and the remaining residuals. A DM RCS system that uses the main engine propellants will have access to much more residuals with less long term hazards and would exploit lunar propellants when they become available. As noted, there are a number of surplus tanks and an array of structural elements that can used to form the core of the hopper.

Scavenged Avionics and power elements can provide system control and communications for high rate real time data and video. The proximity guidance equipment like LIDAR and would be useful but is unavailable from the AM. However, the Outpost DM can provide a hazard avoidance radar.

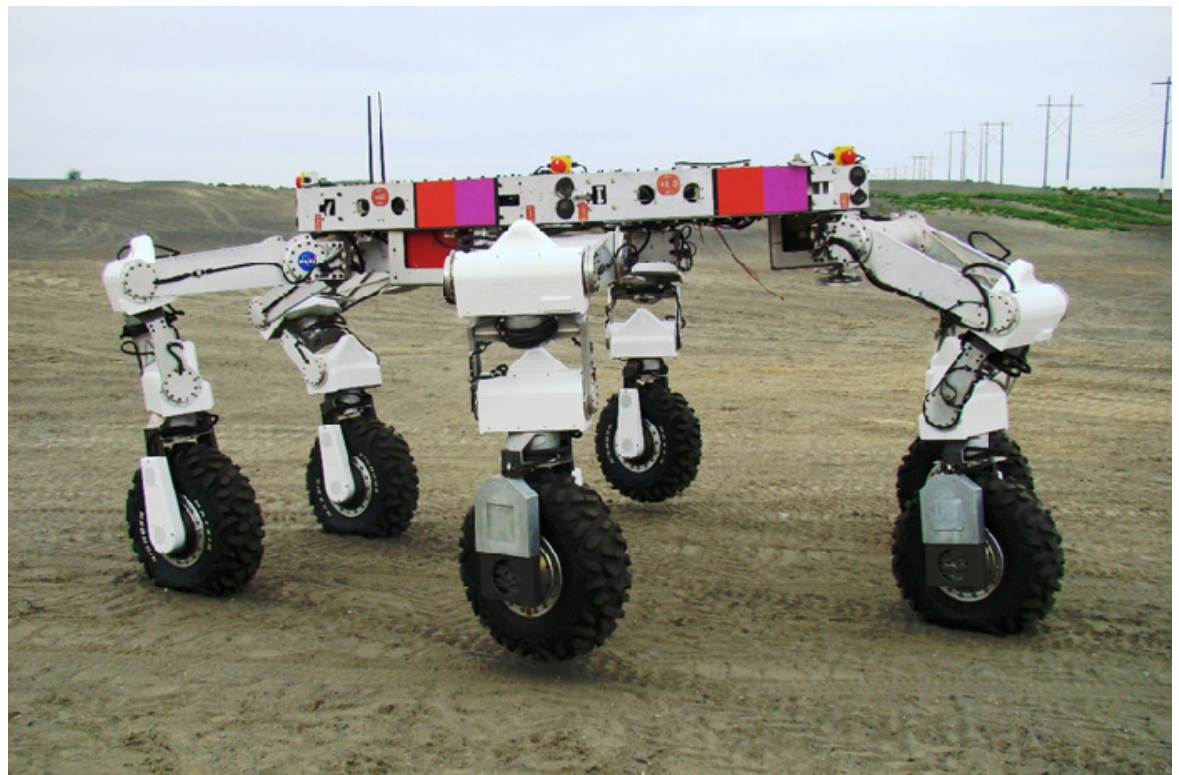

Figure 13: ATHLETE Robot. This prototype is an appropriate scale for conversion to a lunar hopper with scavenged RCS thrusters. (Photo R. Oeftering)

The robotic hopper would need to deliver payloads to the crater site to begin assembling the local infrastructure which would include the first tower element of the cable system and the water collection system. A version of the ATHLETE similar to the scale of the current prototype, shown in the figure, would be suited as both a hopper and as tele-robotic operator. ${ }^{19}$ The current LSS planning shows that the ATHLETE can be coupled with an anthropomorphic robot called "Robonaut". RCS derived thruster system could be designed as a "strap on" capability for the ATHLETE. In this case, LSS robotic elements are merged with scavenged hardware to provide a vast expansion of initial capability. 


\section{The Need for Non Volatile Resources}

It is widely understood that the lunar surface is composed of minerals that may have 40 to $45 \%$ oxygen. ${ }^{20}$ The In-situ resource utilization (ISRU) work so far has focused on this source of oxygen. However, the remaining 55 to $60 \%$ portion that can provide the silicon, iron, aluminum, titanium and many other materials that would be useful in constructing architecture. Currently, there is little ongoing work to extract, separate, and refine these materials. Though scavenging hardware goes a long way toward building infrastructure, ultimately the non volatile resources will make it possible for large scale operations needed for the full commercial development of space.

Assuming that non volatile resource extraction processes are established, the exploitation and applications of insitu metals will reshape exploration. The metals can be used to bootstrap an infrastructure starting with solar power. Solar power further expands the ability to extract materials by high energy methods. With abundant power and metal resources the collection of volatile and non volatile resources can now be expanded by fabricating larger machinery that would otherwise be impossible to deliver from Earth in an affordable manner. With a sprinkling of small amount of high value vitamin technologies the capabilities will eventually match anything currently being built on earth.

The expanding lunar system will produce surpluses that can be exported, such as, water and water derived propellants. Eventually the expanding non volatile production will make it possible to export the metals in the form of in-situ fabricated propellant tanks and structures. With abundant silicon, in situ photovoltaic solar cells can be exported as well.

\section{Reuse of Altair for Cis-Lunar Propellant Delivery}

This paper would be incomplete if it did not discuss how the landers themselves can be reconfigured and reused as a system. With modest modification the landers can be configured as launch vehicles for delivering lunar resources to cis lunar space.

Based on the system reuse analysis the Altair Cargo Lander is the best overall choice for reuse as a propellant delivery system. Although not in the initial design requirements the cargo lander, once refueled has the capacity to launch itself into orbit with cargo. Using simple mass fraction analysis the vehicle could deliver 50 to $60 \%$ of its lift-off mass to orbit. The vehicle system would be loaded with propellants and surplus tanks from other landers would be used as propellant cargo. Due to thrust limitations the engine the mass should be limited to $\$ 55,000 \mathrm{~kg}$.

\section{A. Avionics}

With most of the Cargo Lander avionics systems intact some minor modifications are needed. The Cargo system was never intended for rendezvous so it will need additional GN\&C equipment. The Proximity Operations hardware needed includes optical LIDAR and imaging cameras for ranging and alignment during docking. Additional communications and tracking will be needed to coordinate rendezvous and docking. These can be delivered as a cargo weighing well less than $100 \mathrm{~kg}$. Docking also implies a docking and coupling mechanism. A simplified version of the Altair docking adapter may suffice.

\section{B. Propulsion System Considerations}

The RL-10 engine is a multi-burn system and can be reused if properly preserved after initial landing. The engine would have at least one flight of reliable operation life left. It has very simple needs but the system will need sufficient pressurization from a helium source. Helium is very difficult to chill and although it can be scavenged from multiple landers it will take constant power to maintain the He in a liquid state. If sufficient helium cannot be assured then a system that pressurizes the $\mathrm{H} 2$ tanks by vaporizing hydrogen may be needed. Boost pumps may also be needed on the $\mathrm{O} 2$ side. The feed lines from tanks to engine inlet are typically pre-chilled by liquid helium. A propellant pre-chill of the lines can be used but a couple hundred kilograms of propellant may be lost in the process.

\section{RCS Upgrades}

The cargo lander RCS system is not intended for precision docking maneuvers and will need to be augmented with additional thrusters for lateral motion like the Ascent Module. Residual propellants are expected from each mission but transferring the material poses special hazards. Once again, if the RCS system used the same propellants as the main engine the system would be simpler overall and utilize in-situ propellants. 


\section{Propellant Cargo Tanks}

The propellant cargo can exploit the surplus propulsion system tanks from other landers. Instead of deintegrating an entire lander it would be more practical to reuse the existing system with its supporting structure. In effect, an Outpost Lander is converted into a Propellant Cargo Package. The process would include removing the rocket engine; unneeded structures like the landing gear, the thermal control system. The RCS system may be reused as explained below.

\section{E. Cargo Lander + Propellant Cargo Package Configuration}

A crane or the ATHLETE would be required to handle the Propellant Cargo Package and install it onto the Cargo Lander. The Propellant Cargo Package would utilize the EDS adapter hardware to mate with the Cargo Lander. The overall vehicle mass should not exceed the $55,000 \mathrm{~kg}$. This mass is considerably higher than the Cargo Lander's original landing weight. The combined Cargo Lander and Propellant Cargo Package may also have an abnormally high center of gravity and a RCS system may be needed on both elements. The Cargo Lander should reserve enough propellant to land on the surface again.

This is a notional concept and requires considerable further analysis, including flight dynamics. The Cargo Package would employ scavenged hardware. However, it may prove more effective if a special variant of the Cargo Lander is designed to be re-launched from the surface. For example the landing gear will need to be designed for multiple landings and the RCS system could be enhanced with lateral motion capability for docking. The engine system could be upgraded for longer operating life.

\section{F. Ascent Module Recovery}

The combination of in situ propellants and reused hardware enables one more potential role. That is the recovery of the Ascent Module from orbit once the crew has abandoned it and departed for Earth. The AM will be close to its empty weight at around $3700 \mathrm{~kg}$. A modified and refueled Cargo Lander could be loaded to a total mass of nearly $55,00 \mathrm{~kg}$. Using a mass fraction analysis that considers an ascent rendezvous, docking, de-orbit and landing, the returned mass must be less than $30 \%$ of the launched mass or under $17,000 \mathrm{~kg}$. This is very close to the combined inert mass of both stages.

The Cargo Lander would need a docking adapter for rendezvous and docking with the Ascent Module. The AM ProxOps guidance and RCS system would control the docking process. The Ascent Module would be returned to the lunar surface in an inverted position. This is notional concept but it illustrates what could be accomplished by exploiting used flight hardware in combination with in situ resources to recover and preserve the value of almost all the lunar space assets.

\section{Conclusion}

In this paper the issue of the high cost of flight hardware and the practice of discarding functional hardware is challenged. The high cost with little tangible pay off has plagued NASA from the early Apollo days. An affordable, supportable program cannot be built upon discarded capability. NASA sought to make access to space affordable by developing the reusable Space Shuttle. The Shuttle program has been successful for many missions including delivering and assembling the International Space Station. However, it could not deliver on the promise of low cost access to space. ${ }^{21}$ In fact, no launch vehicle has demonstrated a true low cost access to space.

Providing a tangible benefit from lunar exploration is frustrated by the need to discard stages both to and from the moon. Perfectly good hardware is discarded simply because it is out of fuel. As discussed in the introduction the very little remains at the destination and even less arrives back on Earth. The result is literally billions of dollars worth of discarded hardware after every mission.

There is no simple solution to the high cost of defeating gravity from Earth. The only option is to launch less or launch with less gravity. In the end, only acquiring propellants from in-space sources reduces overall launch mass. The dilemma of how to build an in-situ propellant infrastructure without also becoming a victim of high launch costs requires an innovative approach

In this paper, it is proposed that an affordable program involves a strategy that will minimize launched mass by acquiring the in-situ resources and creating a cis-lunar propellant infrastructure. It is further proposed that the infrastructure can be built by scavenging and fully utilizing every piece of flight hardware to the fullest extent. Tons of flight hardware will be scavenged and re-invested to build capabilities. To minimize costs and deliver much more equipment with fewer discarded stages, it is proposed that the technologies needed must be deployed by robotic cargo missions. 
This paper examined technology options for scavenging flight hardware preserving its value and reusing it in new applications. Some will involve new techniques for manipulating energy and materials. Other technologies must be embedded in the hardware itself.

Ultimately, the technologies will acquire lunar water and deliver it as propellants to Cis-lunar space for the benefit of human space exploration. The ultimate goal is to make exploration and human development of space affordable by first building a space propellant infrastructure that provides broad access to space beyond Earth orbit.

\section{References}

${ }^{1}$ Benton, Sr., M.G., Donahue, B., Caplin, G., Reiley, K., "Configuration Options to Maximize Lunar Surface Reuse of Altair Lander Structure and Systems", AIAA-2009-6405, Space 2009 Conference, Pasadena, CA, 2009.

${ }^{2}$ Fragola J.R., Putney B.F., Pettit D., "Maintainability: The Forgotten "Ility", Essential for Long Term Mission Success", Valador Inc., Herndon, VA, 2008.

${ }^{3}$ Green, J., Spexarth, G., “A Mars-Forward Approach to Lunar Supportability Planning”, AIAA-2009-6427, Space 2009 Conference, Pasadena, CA, 2009.

${ }^{4}$ Oeftering, R.C., Struk, P.M., “A Lunar Surface System Supportability Technology Development Roadmap”, AIAA-2009-6425, Space 2009 Conference, Pasadena, CA, 2009.

${ }^{5}$ Cohen M.M., "From Apollo LM to Altair: Design, Environments, Infrastructure, Missions, and Operations", AIAA-2009-6404, AIAA Space 2009, Pasadena, CA, 2009.

${ }^{6}$ Struk, P.M., Oeftering, R.C., “Approach to In-situ Component Level Electronics Assembly Repair (CLEAR) for Constellation”, AIAA-2009-6472, Space 2009 Conference, Pasadena, CA, 2009.

${ }^{7}$ NASA Constellation Program: Common Avionics and Software Operational Concept Study. May 2010.

${ }^{8}$ McNutt C.J., Vick, R., Whiting, H., Lyke, J., Modular Nano-Satellites - (Plug and Play) PnP CubeSat, AIAA, 7th Responsive Apace Conference. April 2009.

${ }^{9}$ Freitas Jr., R., "Advanced Automation for Space Missions, Proceedings of the 1980 NASA/ASEE Summer Study", 1980.

${ }^{10}$ Taminger, K.M.B., and Hafley, R.A., "Characterization of 2219 Aluminum Produced by Electron Beam Freeform Fabrication," Proceedings of 13th SFF Symposium, Austin, TX, pg 482-489 (2002).

${ }^{11}$ Oeftering, R., NASA, U.S. Patent 5,772,479, "Directional Electrostatic Accretion Process Employing Acoustic Droplet Formation", 1998.

${ }^{12}$ Cadogan D.P., Scarborough S.E.," Rigidized Materials for use in Gossamer Space Inflatable Structures", AIAA2001-1417, $42^{\text {nd }}$ AIAA/ASME/ASCE/AHS/ASC Structures, Structural Dynamics, and Materials Conference, Seattle, WA 2001.

${ }^{13}$ NASA Constellation Program Altair Lunar Lander: LDAC-3 Spacecraft Performance Analysis Report (SPAR), January 2010.

${ }^{14}$ NASA Constellation Program Lunar Lander: LDAC-2 Spacecraft Performance Analysis Report (SPAR), July 2008.

${ }^{15}$ NASA, Mission Operations Directorate- Space Flight Training Division, International Space Station Familiarization Training Manual, ISS FAM C TM 21109, June 3, 2004.

${ }^{16}$ Robinsin, M.S., Jolliff, B., Lawrence, S., "LRO Results and implications for Lunar Science Priorities", Presentation to IPP Decadal Survey, October 2009 http://www.spacepolicyonline.com/pages/images/stories/ PSDS\%20IP2\%20Robinson\%20LRO.pdf

${ }^{17} \mathrm{AWG}$ Aluminum Wire, http://www.interfacebus.com/Aluminum_Wire_AWG_Size.html

${ }^{18}$ Bash, J.F., HANDBOOK OF OCEANOGRAPHIC WINCH, WIRE AND CABLE TECHNOLOGY, Third Edition, National Science Foundation.

${ }^{19}$ Duerk, D.P., “Architecture Student Designs to Support Microhab Sortie Mission”, AIAA-2009-6421, Space 2009 Conference, Pasadena, CA, 2009.

${ }^{20}$ Eckart P. "The Lunar Base Handbook: An Introduction to Lunar Base Design”, McGraw-Hill, New York, NY, 2000.

${ }^{21}$ Zapata, E., Levack, D.J., Rhodes, R.E., Robinson, J.W., "Shuttle Shortfalls and Lessons Learned for the Sustainment of Human Space Exploration", AIAA-2009-5346, AIAA/ASME/SAE/ASEE Joint Propulsion Conference, Denver, Co., 2009. 


\begin{tabular}{|c|c|c|}
\hline \multicolumn{2}{|c|}{ REPORT DOCUMENTATION PAGE } & $\begin{array}{l}\text { Form Approved } \\
\text { OMB No. 0704-0188 }\end{array}$ \\
\hline \multicolumn{3}{|c|}{$\begin{array}{l}\text { The public reporting burden for this collection of information is estimated to average } 1 \text { hour per response, including the time for reviewing instructions, searching existing data sources, gathering and maintaining the } \\
\text { data needed, and completing and reviewing the collection of information. Send comments regarding this burden estimate or any other aspect of this collection of information, including suggestions for reducing this } \\
\text { burden, to Department of Defense, Washington Headquarters Services, Directorate for Information Operations and Reports (070704-0188), } 1215 \text { Jefferson Davis Highway, Sulte } 1204 \text {, Arlington, VA } 222202-4302 \text {. } \\
\text { Respondents should be aware that notwithstanding any other provision of law, no person shall be subject to any penalty for failing to comply with a collection of information if it does not display a currently valid OMB } \\
\text { control number. } \\
\text { PLEASE DO NOT RETURN YOUR FORM TO THE ABOVE ADDRESS. }\end{array}$} \\
\hline $\begin{array}{l}\text { 1. REPORT DATE (DD-MM-YYYY) } \\
01-01-2011\end{array}$ & $\begin{array}{l}\text { 2. REPORT TYPE } \\
\text { Technical Memorandum }\end{array}$ & 3. DATES COVERED (From - To) \\
\hline \multirow{3}{*}{\multicolumn{2}{|c|}{$\begin{array}{l}\text { 4. TITLE AND SUBTITLE } \\
\text { The Impact of Flight Hardware Scavenging on Space Logistics }\end{array}$}} & 5a. CONTRACT NUMBER \\
\hline & & 5b. GRANT NUMBER \\
\hline & & 5c. PROGRAM ELEMENT NUMBER \\
\hline \multirow{3}{*}{\multicolumn{2}{|c|}{$\begin{array}{l}\text { 6. AUTHOR(S) } \\
\text { Oeftering, Richard, C. }\end{array}$}} & 5d. PROJECT NUMBER \\
\hline & & 5e. TASK NUMBER \\
\hline & & $\begin{array}{l}\text { 5f. WORK UNIT NUMBER } \\
\text { WBS } 825855.01 .03 .03 .03\end{array}$ \\
\hline \multicolumn{2}{|c|}{$\begin{array}{l}\text { 7. PERFORMING ORGANIZATION NAME(S) AND ADDRESS(ES) } \\
\text { National Aeronautics and Space Administration } \\
\text { John H. Glenn Research Center at Lewis Field } \\
\text { Cleveland, Ohio 44135-3191 }\end{array}$} & $\begin{array}{l}\text { 8. PERFORMING ORGANIZATION } \\
\text { REPORT NUMBER } \\
\text { E-17467 }\end{array}$ \\
\hline \multirow{2}{*}{\multicolumn{2}{|c|}{$\begin{array}{l}\text { 9. SPONSORING/MONITORING AGENCY NAME(S) AND ADDRESS(ES) } \\
\text { National Aeronautics and Space Administration } \\
\text { Washington, DC 20546-0001 }\end{array}$}} & $\begin{array}{l}\text { 10. SPONSORING/MONITOR'S } \\
\text { ACRONYM(S) } \\
\text { NASA }\end{array}$ \\
\hline & & $\begin{array}{l}\text { 11. SPONSORING/MONITORING } \\
\text { REPORT NUMBER } \\
\text { NASA/TM-2011-216888 }\end{array}$ \\
\hline \multicolumn{3}{|c|}{$\begin{array}{l}\text { 12. DISTRIBUTION/AVAILABILITY STATEMENT } \\
\text { Unclassified-Unlimited } \\
\text { Subject Category: } 20 \\
\text { Available electronically at http://www.sti.nasa.gov } \\
\text { This publication is available from the NASA Center for AeroSpace Information, 443-757-5802 }\end{array}$} \\
\hline
\end{tabular}

13. SUPPLEMENTARY NOTES

\section{ABSTRACT}

For a given fixed launch vehicle capacity the logistics payload delivered to the moon may be only roughly 20 percent of the payload delivered to the International Space Station (ISS). This is compounded by the much lower flight frequency to the moon and thus low availability of spares for maintenance. This implies that lunar hardware is much more scarce and more costly per kilogram than ISS and thus there is much more incentive to preserve hardware. The Constellation Lunar Surface System (LSS) program is considering ways of utilizing hardware scavenged from vehicles including the Altair lunar lander. In general, the hardware will have only had a matter of hours of operation yet there may be years of operational life remaining. By scavenging this hardware the program, in effect, is treating vehicle hardware as part of the payload. Flight hardware may provide logistics spares for system maintenance and reduce the overall logistics footprint. This hardware has a wide array of potential applications including expanding the power infrastructure, and exploiting in-situ resources. Scavenging can also be seen as a way of recovering the value of, literally, billions of dollars worth of hardware that would normally be discarded. Scavenging flight hardware adds operational complexity and steps must be taken to augment the crew's capability with robotics, capabilities embedded in flight hardware itself, and external processes. New embedded technologies are needed to make hardware more serviceable and scavengable. Process technologies are needed to extract hardware, evaluate hardware, reconfigure or repair hardware, and reintegrate it into new applications. This paper also illustrates how scavenging can be used to drive down the cost of the overall program by exploiting the intrinsic value of otherwise discarded flight hardware.

\section{SUBJECT TERMS}

Logistics; Flight operations; Space architecture; Supportability; Lunar; In situ resource

\begin{tabular}{|c|c|c|c|c|c|}
\hline \multicolumn{3}{|c|}{ 16. SECURITY CLASSIFICATION OF: } & $\begin{array}{l}\text { 17. LIMITATION OF } \\
\text { ABSTRACT } \\
\text { UU }\end{array}$ & $\begin{array}{l}\text { 18. NUMBER } \\
\text { OF } \\
\text { PAGES } \\
32\end{array}$ & $\begin{array}{l}\text { 19a. NAME OF RESPONSIBLE PERSON } \\
\text { STI Help Desk (email:help@sti.nasa.gov) } \\
\text { 19b. TELEPHONE NUMBER (include area code) } \\
\text { 443-757-5802 }\end{array}$ \\
\hline
\end{tabular}



